\title{
Chiral phosphines in nucleophilic organocatalysis
}

\author{
Yumei Xiao ${ }^{1}$, Zhanhu Sun ${ }^{1}$, Hongchao Guo ${ }^{* 1}$ and Ohyun Kwon ${ }^{* 2}$
}

Open Access

\author{
Review \\ Address: \\ 1Department of Applied Chemistry, China Agricultural University, \\ Beijing 100193, P. R. China and ${ }^{2}$ Department of Chemistry and \\ Biochemistry, University of California, Los Angeles, CA 90095, USA \\ Email: \\ Hongchao Guo* - hchguo@cau.edu.cn; Ohyun Kwon* - \\ ohyun@chem.ucla.edu \\ * Corresponding author \\ Keywords: \\ asymmetric catalysis; chiral phosphine; nucleophilic; organocatalysis; \\ organophosphorus; synthesis
}

Beilstein J. Org. Chem. 2014, 10, 2089-2121.

doi:10.3762/bjoc. 10.218

Received: 03 April 2014

Accepted: 01 August 2014

Published: 04 September 2014

This article is part of the Thematic Series "Organophosphorus chemistry".

Guest Editor: P. R. Hanson

(C) 2014 Xiao et al; licensee Beilstein-Institut.

License and terms: see end of document.

\begin{abstract}
This review discusses the tertiary phosphines possessing various chiral skeletons that have been used in asymmetric nucleophilic organocatalytic reactions, including annulations of allenes, alkynes, and Morita-Baylis-Hillman (MBH) acetates, carbonates, and ketenes with activated alkenes and imines, allylic substitutions of MBH acetates and carbonates, Michael additions, $\gamma$-umpolung additions, and acylations of alcohols.
\end{abstract}

\section{Introduction}

During the past two decades, tertiary phosphine catalysts have been applied extensively in a wide range of carbon-carbon and carbon-heteroatom bond-forming transformations [1-18]. Many phosphine-catalyzed reactions have been developed for the syntheses of various biologically important acyclic and cyclic molecules. Asymmetric variants of these reactions have evolved relatively slowly. Indeed, very little research on chiral tertiary phosphine-catalyzed asymmetric reactions occurred prior to the year 2000 [19,20]. Over the last decade, however, and especially since 2005 , considerable progress has been made in asymmetric phosphine catalysis. As a result, phosphinecatalyzed asymmetric reactions are now powerful and versatile tools for the construction of $\mathrm{C}-\mathrm{C}, \mathrm{C}-\mathrm{N}, \mathrm{C}-\mathrm{O}$, and $\mathrm{C}-\mathrm{S}$ bonds and for the syntheses of functionalized carbocycles and heterocycles $[11,13,14]$. In offering a general account of this field, herein we summarize the major developments in nucleophilic chiral phosphine-catalyzed asymmetric reactions, including annulations of allenes, ketenes, alkynes, and Morita-Baylis-Hillman (MBH) carbonates with activated alkenes and imines, allylic substitution of $\mathrm{MBH}$ acetates and carbonates, Michael additions, $\gamma$-umpolung additions, and acylations of alcohols. Our discussion is organized according to the structural features of the chiral phosphines, the reaction types, and the nature of the substrate. Because chiral phosphinepromoted Rauhut-Currier (RC) reactions $[9,10]$ and MBH/aza$\mathrm{MBH}$ reactions [21-26] have been summarized splendidly in several reviews, we do not cover these transformations, except for selected examples related to other reactions. 


\section{Review}

\section{Chiral phosphine catalysts}

Nucleophilic phosphine catalysis often involves the formation of Lewis adducts, namely phosphonium (di)enolate zwitterions, as reaction intermediates $[1,3,6,17]$. These intermediates are formed through nucleophilic attack of the phosphine catalysts at electron-poor nuclei (normally carbon atoms) and then proceed through several steps to form new chemical bonds. Generally, the efficiency of nucleophilic phosphine catalysis often depends on the nature of the tertiary phosphine. Although many reactions require more nucleophilic trialkylphosphines as catalysts, only a few chiral trialkylphosphines are available. The synthesis of novel trialkylphosphines can be quite difficult, thereby limiting the scope of their chiral variants. Moreover, because of inherent air-sensitivity, the storage of trialkylphosphines can be problematic. On the other hand, thousands of arylphosphines have been used as chiral ligands for metal-catalyzed asymmetric reactions [27-30]. Most of these phosphines are acyclic, usually possess low nucleophilic activity, and generally display poor enantioselectivities for phosphine organocatalysis. For example, 2,2'-bis(diphenylphosphino)-1,1'-binaphthyl (BINAP) is an excellent chiral diphosphine ligand for metal-catalyzed asymmetric reactions, but it displays extremely poor reactivity and enantioselectivity in many nucleophilic phosphinecatalyzed reactions. For these reasons, effective chiral catalysts for nucleophilic phosphine catalysis are scarce, seriously limiting the development of asymmetric variants. At present, the synthesis of new chiral phosphines designed specifically for nucleophilic organocatalysis remains a significant challenge.

In the early exploration stage of asymmetric nucleophilic phosphine organocatalysis, chiral phosphines that had originally been designed as ligands for metal-catalyzed reactions were selected and examined for their reactivity. Although several cyclic phosphines were found to have excellent catalytic activities and enantioselectivities, only a few acyclic phosphines were effective. In this context, inspired by polyfunctional chiral small-molecule catalysts, particularly amino acid and thioureabased systems [31,32], multifunctional chiral phosphines were constructed by installing a nucleophilic phosphine and a hydrogen bonding moiety on a molecular chiral backbone. These units served as active functional groups to synergistically activate the substrates in an assembled chiral environment, providing excellent catalytic activities and enantioselectivities that could not be accomplished using conventional chiral phosphines lacking hydrogen bonding moieties. Such multifunctional phosphines are readily accessible from simple chiral starting materials through a molecular building block approach, allowing combinatorial syntheses of new multifunctional chiral phosphines with diversity and, consequently, improving the probability of discovering an excellent catalyst.

In this review, we divide chiral phosphines into three classes: cyclic phosphines (Figures 1-5), acyclic phosphines (Figure 6), and multifunctional acyclic phosphines (Figures 7 and 8). Generally, the cyclic phosphines have been constructed based on bridged-ring (Figure 1), binaphthyl (Figure 2), ferrocene (Figure 3), spirocyclic (Figure 4), and five-membered phospholane ring (Figure 5) skeletons. Multifunctional chiral phosphines have generally been constructed based on binaphthyl

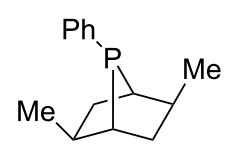

A1

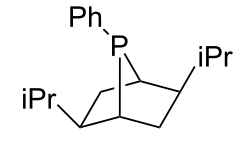

A2

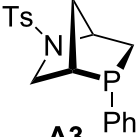

A3 $\mathrm{Ph}$
Figure 1: Cyclic chiral phosphines based on bridged-ring skeletons.<smiles>[R]P1Cc2ccc3ccccc3c2-c2c(ccc3ccccc23)CP([R])C1</smiles><smiles></smiles>

B4<smiles>CCN1Cc2ccc3ccccc3c2-c2c(ccc3ccccc23)C1</smiles>

B5

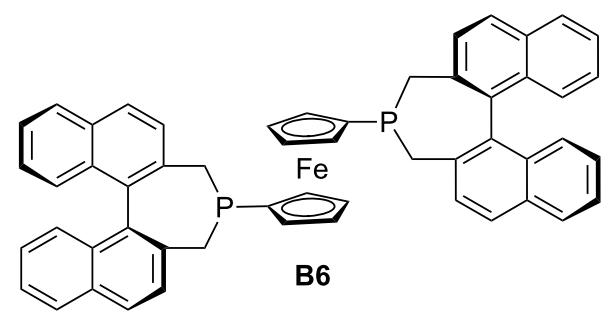<smiles></smiles>

Figure 2: Cyclic chiral phosphines based on binaphthyl skeletons. 


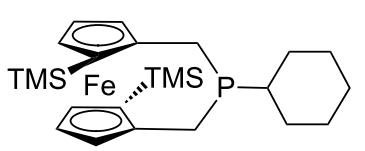

C1

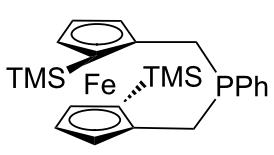

C2

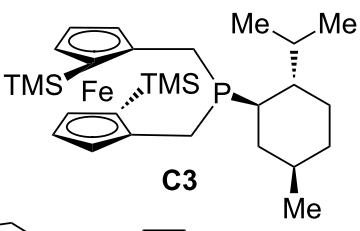

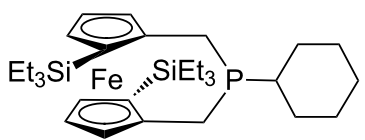

C4

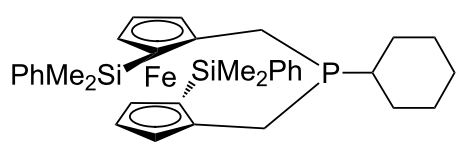

C5

Figure 3: Cyclic chiral phosphines based on ferrocene skeletons.<smiles>c1ccc(P(Cc2cccc3c2C2CCCc4cccc2c4-3)c2ccccc2)cc1</smiles>

D1<smiles>c1ccc(P2Cc3cccc4c3C3(CCC4)Cc4cccc(c43)C2)cc1</smiles>

D2<smiles>COc1cc(P2Cc3cccc4c3C3(CC4)c4cccc(c43)C2)cc(C)c1C</smiles>

D3

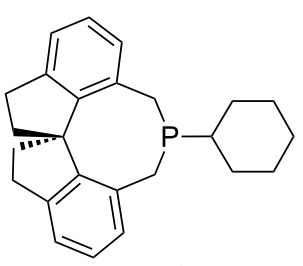

D4

Figure 4: Cyclic chiral phosphines based on spirocyclic skeletons.<smiles>c1ccc(C2CCP(C3CCC(c4ccccc4)P3CCP3[C@H](c4ccccc4)CC[C@@H]3c3ccccc3)CCP2C(c2ccccc2)c2ccccc2)cc1</smiles>

(-)-E1<smiles>[R]C1CCC([R])P1c1ccccc1</smiles>

$\mathrm{E} 4: \mathrm{R}=\mathrm{Me}$ E5: $R=E t$

$(+)-E 1$<smiles>CC(C)(C)PC1CCCC1C1CCCP1C(C)(C)C</smiles>

E6<smiles>CC[C@@H]1CC[C@@H](F)P1c1ccccc1P1[C@H](CC)CC[C@H]1CC</smiles>

E7<smiles>Pc1ccccc1</smiles>

E2<smiles>Pc1cccp1CC[C@H]1[CH]CCC1</smiles>

E3

Figure 5: Cyclic chiral phosphines based on phospholane ring skeletons.

skeletons (Figure 7) and amino acids (Figure 8). These structurally different chiral phosphines can be selected to catalyze appropriate asymmetric nucleophilic reactions. The electronic and steric properties of these phosphines can be tailored elaborately through modification of functional groups and the introduction of chiral elements, thereby providing suitable chirality, nucleophilicity, basicity, functionality, and rigidity.

\section{Enantioselective reactions catalyzed by chiral phosphines}

Using the chiral phosphines described above as catalysts, a number of highly enantioselective reactions have been achieved, offering a wide variety of methods for enantioselect-<smiles>CC1(C)OC(CPc2ccccc2)C(CPc2ccccc2)O1</smiles>

F1<smiles>Pc1cccc(Pc2ccccc2)c1P</smiles>

F3

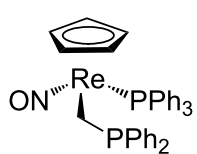

F4<smiles>COc1ccccc1P(CCP(c1ccccc1)c1ccccc1)c1ccccc1</smiles>

F2
Figure 6: Acyclic chiral phosphines. 


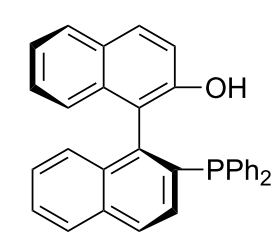

G1

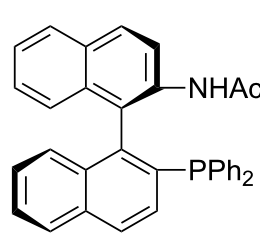

G2

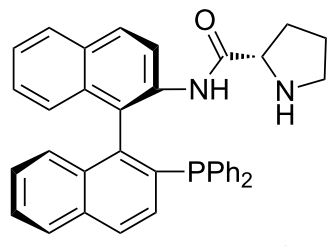

G3<smiles>C/C=C\C=C/C=C/C=C/c1ccc2ccccc2c1-c1c(NC(=O)[O-])ccc2ccccc12</smiles><smiles>CS(=O)(=O)Nc1ccc2ccccc2c1-c1c(-c2ccccc2)ccc2ccccc12</smiles>

G5

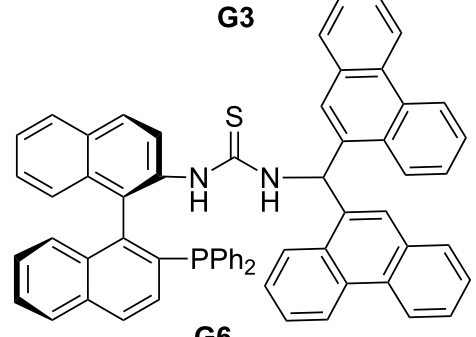

G6<smiles>S=C(Nc1ccc2ccccc2c1-c1cccc2ccccc12)NC(c1ccccc1)c1ccccc1</smiles>

G7<smiles>Cc1cc(C)cc(P(c2cc(C)cc(C)c2)c2ccc3ccccc3c2-c2c(NC(=S)NCc3ccccc3)ccc3ccccc23)c1</smiles>

G8<smiles>[Y]P(c1ccccc1)N1Cc2ccc3ccccc3c2-c2c(ccc3ccccc23)C1</smiles>

G9

Figure 7: Multifunctional chiral phosphines based on binaphthyl skeletons.<smiles>CC(C)C(CC(=O)c1cc(C(F)(F)F)cc(C(F)(F)F)c1)NC(=O)c1ccccc1</smiles><smiles>CCC(Cc1ccccc1)NC(=O)c1cc(F)cc(F)c1</smiles>

H6<smiles>CC(C)C(Cc1ccccc1)NC(=O)c1cc(C(F)(F)F)cc(C(F)(F)F)c1</smiles>

H7<smiles>CC(O)C(Cc1ccccc1)NC(=O)c1cc(C(F)(F)F)cc(C(F)(F)F)c1</smiles>

H8: $\mathrm{R}=\mathrm{TMS} ; \mathrm{H9}: \mathrm{R}=\mathrm{H}$

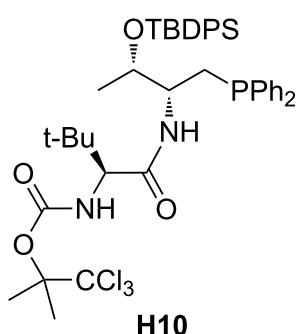

H10

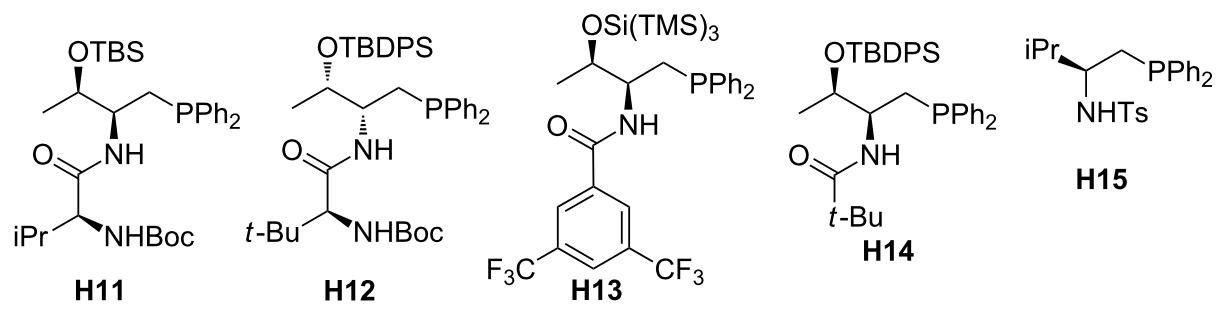

Figure 8: Multifunctional chiral phosphines based on amino acid skeletons. 
ive syntheses of structurally diverse acyclic, carbocyclic, and heterocyclic compounds.

\section{$2.1[3+2]$ Annulation of allenes with activated alkenes}

Nucleophilic phosphine-catalyzed annulations have been established as very useful tools for the syntheses of carbo- and heterocycles from simple starting materials [1-17]. Although a diverse set of annulations, including $[2+1],[2+2],[4+1]$, $[3+2],[2+2+1],[2+2+2],[3+2+3],[3+3],[4+2]$, $[4+3],[6+3],[8+2]$, and $[8+3]$ annulations, has been developed, asymmetric variants exist for only a few of them. In particular, chiral phosphine-catalyzed [3 +2$]$ annulations of allenes, alkynes, and $\mathrm{MBH}$ adducts with electron-deficient olefins and imines, resulting in cyclopentenes and pyrrolidines, have been the most studied, with many successful reported examples.

2.1.1 [3 + 2] Annulations using cyclic phosphines as chiral catalysts: The first appearance in the literature of a chiral phosphine-catalyzed annulation was reported by Zhang and co-workers in 1997 [33]. Based on Lu's work on phosphinecatalyzed annulation [34], Zhang et al. employed (Scheme 1) a chiral bicyclic phosphine $\mathbf{A 2}$ to achieve asymmetric [3+2] annulations between several allenoates and electron-deficient olefins in benzene at room temperature with excellent regioselectivities $(1: 2>94 / 6)$ and enantioselectivities $(1,69-93 \%$ ee). This catalyst features a rigid bridged [2.2.1] bicyclic structure. The excellent regioselectivities and enantioselectivities resulted from the existence of the two isopropyl substituents in the chiral phosphine A2, which effectively controlled the approach of the acrylate toward the plausible phosphine/allenoate zwitterionic intermediate. Although the yields were not always very high, this inspiring study provided invaluable insight into asymmetric annulations catalyzed by chiral phosphines.

Until 2006, almost one decade later, no reports appeared of novel phosphine-catalyzed asymmetric $[3+2]$ annulations. Then, using a chiral phosphepine B1 based on a binaphthyl skeleton, $\mathrm{Fu}$ and co-workers developed the first asymmetric $[3+2]$ annulation of ethyl allenoate with various $\alpha, \beta$-unsaturated enones to provide functionalized cyclopentenes (Scheme 2) [35]. The key structural feature of the chiral catalyst B1 is its rigid binaphthyl skeleton. This approach allowed the preparation of a wide array of cyclopentenes with two adjacent chiral centers, with good enantiomeric excesses and satisfactory to good regioselectivities. These transformations were slightly influenced by electronic effects. Notably, Fu et al. successfully applied this approach to construct spirocyclic compounds containing two neighboring quaternary and tertiary stereocenters in modest to excellent yields (up to 97\%) and high enantioselectivities (up to $95 \%$ ee).

Subsequently, the Fu group applied this approach to the [3+2] annulation of allenes with 1,1-disubstituted olefins to synthesize highly functionalized cyclopentenes that bear an array of heteroatom-substituted quaternary stereocenters [36]. From a screening of catalysts, they carefully examined the effect of substitution of the binaphthyl framework of chiral phosphines, identifying the 3,3'-diphenyl-substituted phosphepine $\mathbf{B 4}$ as the

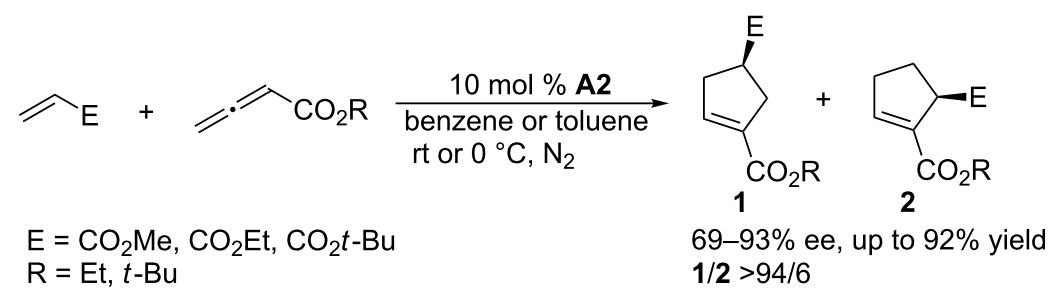

Scheme 1: Asymmetric [3 + 2] annulations of allenoates with electron-deficient olefins, catalyzed by the chiral bicyclic phosphine A2.

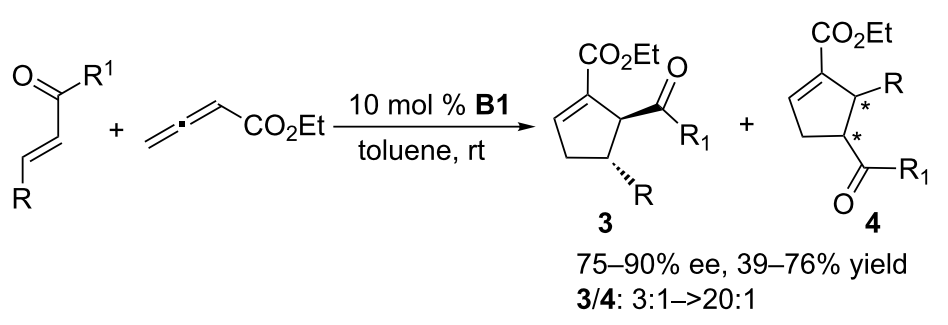


optimal catalyst. Based on the X-ray crystal structure of the catalyst, they proposed that the chiral microenvironment of the binaphthyl-based phosphepine was amplified by its 3,3'diphenyl substituents. In the presence of the chiral phosphepine B4, the reactions of allenes with electron-deficient 1,1-disubstituted olefins proceeded smoothly to give functionalized cyclopentenes in satisfactory yields with up to $98 \%$ ee (Scheme 3). That study extended the substrate scope of known asymmetric phosphine-catalyzed [3+2] annulation reactions to diverse heteroatom-substituted olefins and allenamides. Nitrogen-, phosphorus-, oxygen-, and sulfur-substituted olefins and allenamides were compatible with these B4-catalyzed reactions. Fu's results provided useful hints for further expansion of the substrate scope.

Using B2 as the chiral catalyst, Marinetti and co-workers also developed several asymmetric [3+2] annulations of allenoates with activated alkenes. In the presence of chiral phosphine B2, the [3 + 2] annulations between allenoates and 2-aryl-1,1-dicyanoethylenes allowed convenient syntheses of functionalized cyclopentenes with both aryl and heteroaryl substituents on the stereogenic carbon atom, in high yields and with up to $90 \%$ ee (Scheme 4) [37]. 3-Alkylideneindolin-2-ones underwent [3 + 2] annulations with allenoates, affording various biologically relevant spirocyclic oxindolic cyclopentanes in excellent yields and greater than $97 \%$ ee (Scheme 5) [38]. Enantioselective [3 + 2] annulations of 4-substituted 2,6-diarylidenecyclohexanones with allenoates occurred with high diastereo- and enantioselectivity, providing spirocyclic compounds in satisfactory yields with up to $92 \%$ ee (Scheme 6) [39]. Using the catalyst B2, Jørgensen and co-workers developed a sequential annulation/alcoholysis reaction. Alkylidene azlactones, among the most widely used starting materials for the syntheses of quaternary amino acids, were cyclized with ethyl allenoate and, subsequently, alcoholyzed in situ to afford highly functionalized, optically active amino esters in moderate to good yields and with $79-94 \%$ ee (Scheme 7) [40].

Very interestingly, when using the chiral phosphine $(S, S)-f$ binaphane $\mathbf{B 6}$ as the catalyst, [60]fullerene also reacted with

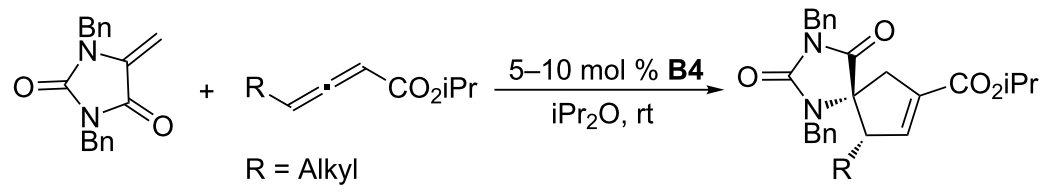

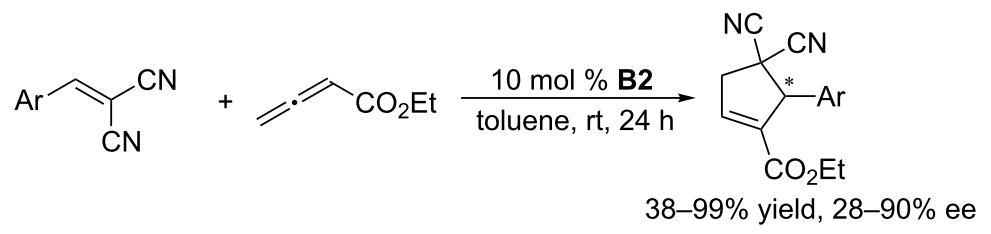

Scheme 4: Asymmetric [3 + 2] annulations of 2-aryl-1,1-dicyanoethylenes with ethyl allenoate, catalyzed by the chiral binaphthyl-based phosphepine B2.

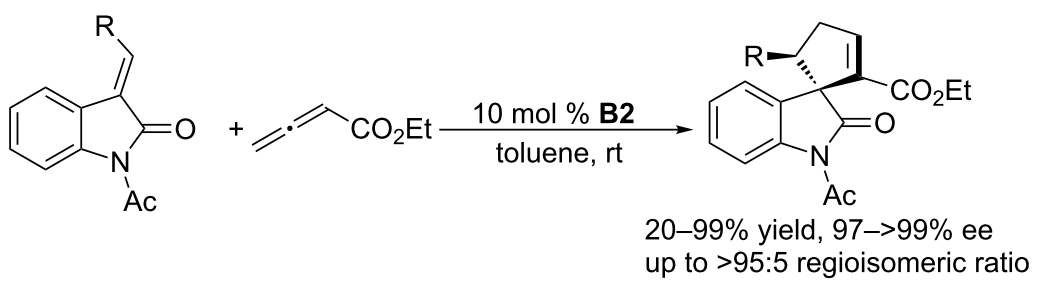


<smiles>[R]C1CC(=C[PH2+][CH-]C(C)C)C(=O)C(=Cc2ccccc2)C1</smiles>

$\mathrm{R}^{1}=\mathrm{Me}, t-\mathrm{Bu}$
$\mathrm{R}^{2}=\mathrm{Et}, t-\mathrm{Bu}$

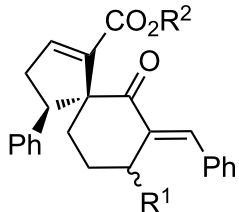

$20-75 \%$ yield, $82-92 \%$ ee up to $>95: 5 \mathrm{dr}$

Scheme 6: Asymmetric [3 + 2] annulations of 2,6-diarylidenecyclohexanones with allenoates, catalyzed by the chiral binaphthyl-based phosphepine B2.

$$
\begin{aligned}
& \text { 急 } \\
& 47-58 \% \text { yield, } 79-95 \% \text { ee } \\
& 7: 2 \text { to } 9: 1 \text { regioisomeric ratio }
\end{aligned}
$$

Scheme 7: Asymmetric [3 + 2] annulations of allenoate with alkylidene azlactones, catalyzed by the chiral binaphthyl-based phosphepine B2, and subsequent alcoholysis in methanol.

allenoates at room temperature, providing a wide range of optically pure $(S)$-cyclopenteno[60]fullerenes in up to $99 \%$ ee (Scheme 8) [41]. This study provided a versatile and promising strategy for tailoring carbon materials (e.g., fullerenes, carbon nanotubes), imparting them with desired properties for applications in materials chemistry $[42,43]$.

To further develop nucleophilic phosphine-catalyzed asymmetric reactions, Marinetti and co-workers synthesized a series of ferrocene-modified planar chiral phosphines featuring a new skeleton (Figure 3) $[44,45]$. Among these compounds, the $P$-cyclohexyl phosphine $\mathbf{C 1}$ proved to be the most efficient catalyst for [3+2] cycloadditions of ethyl 2,3-butadienoate with activated enones, fumarate esters, and acrylates. In the presence of $10 \mathrm{~mol} \%$ of the catalyst in toluene at room temperature, the $[3+2]$ annulations of allenoates with alkenes proceeded smoothly, providing functionalized cyclopentenes in moderate to good yields (up to 87\%) with excellent enantio- selectivities (87-96\% ee) and regioisomeric ratios of up to $>20: 1$ (Scheme 9) [44,45]. The bulky ferrocene was presumably responsible for the high enantioselectivities. Notably, the presence of the electron-rich ferrocene unit inhibited oxidation of the phosphines, imparting them with air-stability and easy-to-handle properties [45]. Subsequently, Marinetti and co-workers found that these chiral phosphines had very broad substrate scope and could be applied in $[3+2]$ annulations of allenes with various activated alkenes. For example, the chiral phosphine $\mathbf{C 1}$ mediated [3 + 2] annulations of a range of di- and trisubstituted alkenes with allenes under mild conditions, providing a variety of functionalized cyclopentenes, cyclopentenylphosphonates, spirooxindoles, heterocyclic spiranes, cyclopentene-fused chromanones, and dihydroquinolinones enantioselectively (Schemes 10-17) [38,39,46-48]. These products can be quite biologically active and many have been applied in medicine and other fields.

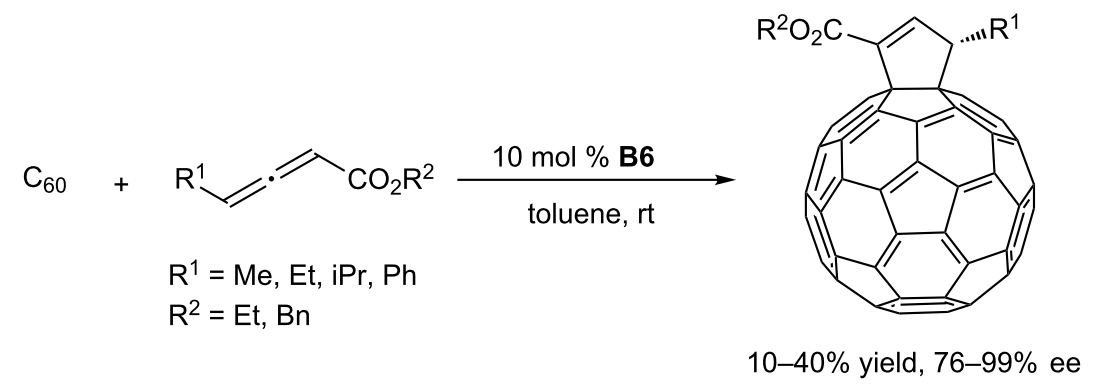

Scheme 8: Asymmetric $[3+2]$ annulations of $\mathrm{C}_{60}$ with allenoates, catalyzed by the chiral phosphine $\mathbf{B 6}$. 
<smiles>[R]C=CC([R])=O</smiles>

$\mathrm{R}^{1}=\mathrm{H}, \mathrm{Ph}, \mathrm{CO}_{2} \mathrm{Et}$, 1-naphthyl, 4- $\mathrm{MeOC}_{6} \mathrm{H}_{4}, \quad$ up to $87 \%$ yield, $87-96 \%$ ee 4- $\mathrm{NO}_{2} \mathrm{C}_{6} \mathrm{H}_{4}$, 2-furyl, 2-quinolyl, alkynyl up to $>20: 1$ regioisomeric ratio $\mathrm{R}^{2}=\mathrm{OEt}, \mathrm{Ph}, 4-\mathrm{CH}_{3} \mathrm{OC}_{6} \mathrm{H}_{4}, 4-\mathrm{NO}_{2} \mathrm{C}_{6} \mathrm{H}_{4}$

Scheme 9: Asymmetric $[3+2]$ annulations of $\alpha, \beta$-unsaturated esters and ketones with an allenoate, catalyzed by the ferrocene-modified phosphine C1.

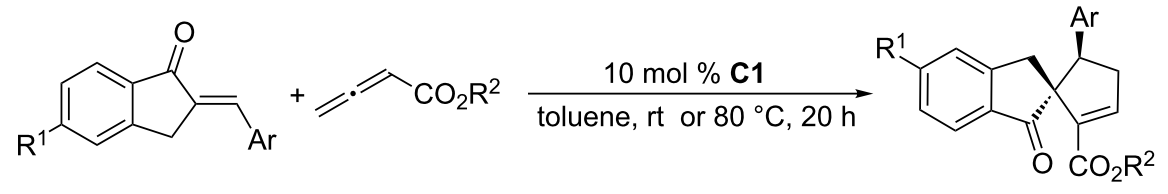

$\mathrm{R}^{1}=\mathrm{H}, \mathrm{Me}, \mathrm{Br} ; \mathrm{R}^{2}=\mathrm{Et}, \mathrm{Bn}, \mathrm{Cy}$

$30-87 \%$ yield, $77-85 \%$ ee

$\mathrm{Ar}=\mathrm{Ph}, 1$-naphthyl, $4-\mathrm{ClC}_{6} \mathrm{H}_{4}$

Scheme 10: Asymmetric [3 +2$]$ annulations of exocyclic enones with allenoates, catalyzed by the ferrocene-modified phosphine $\mathbf{C 1}$.

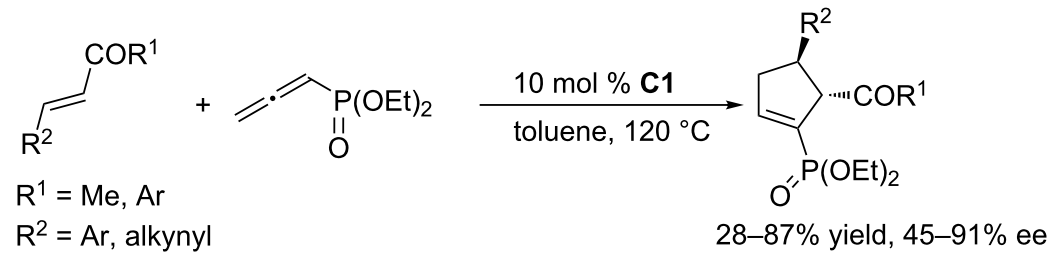

Scheme 11: Asymmetric [3+2] annulations of enones with an allenylphosphonate, catalyzed by the ferrocene-modified phosphine $\mathbf{C} 1$.

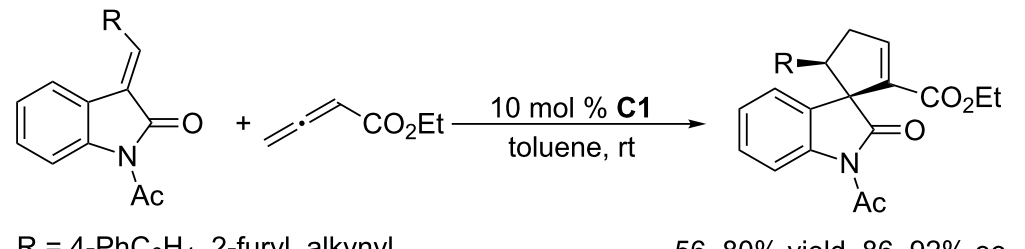

$\mathrm{R}=4-\mathrm{PhC}_{6} \mathrm{H}_{4}, 2$-furyl, alkynyl

$56-80 \%$ yield, $86-92 \%$ ee up to $92: 8$ regioisomeric ratio

Scheme 12: Asymmetric [3 + 2] annulations of 3-alkylidene-oxindoles with ethyl allenoate, catalyzed by the ferrocene-modified phosphine C1.

$$
\begin{aligned}
& \sim_{\mathrm{Ar}^{2}}+=\mathrm{CO}_{2} \mathrm{Et} \underset{\text { toluene, rt, 24h }}{10 \mathrm{~mol} \% \mathrm{C1}} \\
& 55-80 \% \text { yield, } 92-93 \% \text { ee }
\end{aligned}
$$

Scheme 13: Asymmetric [3 + 2] annulations of dibenzylideneacetones with ethyl allenoate, catalyzed by the ferrocene-modified phosphine C1. 


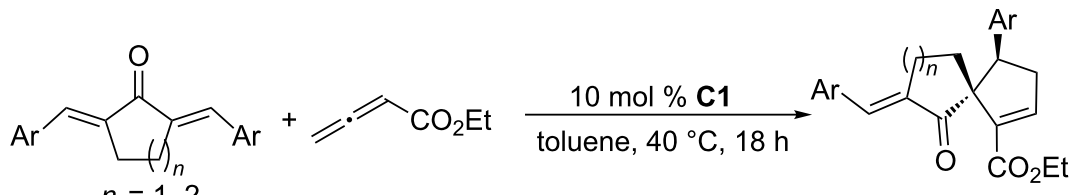

$35-90 \%$ yield, $84-92 \%$ ee

Scheme 14: Asymmetric [3 + 2] annulations of trisubstituted alkenes with ethyl allenoate, catalyzed by the ferrocene-modified phosphine $\mathbf{C 1}$.

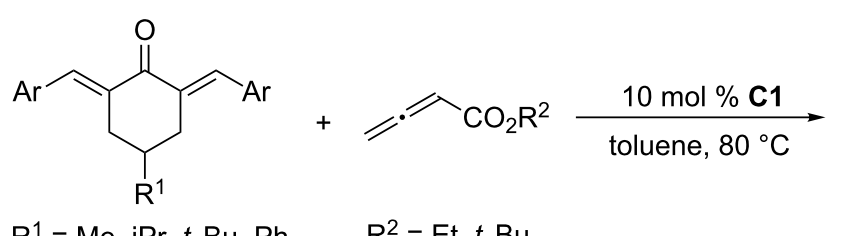

$\mathrm{R}^{1}=\mathrm{Me}, \mathrm{PPr}, t-\mathrm{Bu}, \mathrm{Ph} \quad \mathrm{R}^{2}=\mathrm{Et}, t-\mathrm{Bu}$

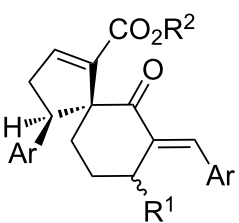

$44-98 \%$ yield, $75-95 \%$ ee up to $>95: 5 \mathrm{dr}$

Scheme 15: Asymmetric [3 + 2] annulations of 2,6-diarylidenecyclohexanones with allenoates, catalyzed by the ferrocene-modified phosphine $\mathbf{C 1}$.

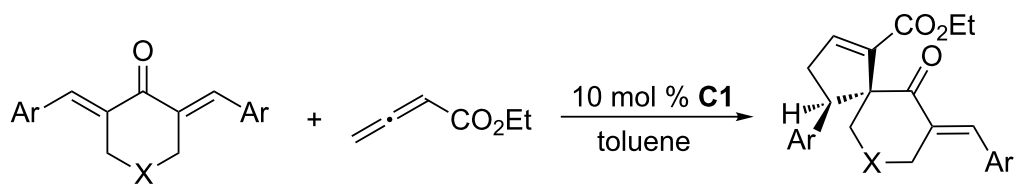<smiles>[R]OC([R])c1cc2c[R]([R])ccc2oc1=O</smiles>

$\mathrm{R}=\mathrm{H}, 7-\mathrm{MeO}, 8-\mathrm{MeO}, 8-\mathrm{Br}, 8-\mathrm{NO}_{2}$

$\mathrm{R}^{1}=\mathrm{Me}, \mathrm{Et}, \mathrm{Cy}$

$\mathrm{R}^{2}=\mathrm{Et}, \mathrm{Bn}, \mathrm{Cy}$<smiles>[R]OC(=O)C1=CCC2(O[R20])C(=O)Oc3cc[R]([R])cc3C12</smiles>

$45-84 \%$ yield, $53-76 \%$ ee 3:1-5:1 regioisomeric ratio

Scheme 17: Asymmetric $[3+2]$ annulations of $\alpha, \beta$-unsaturated esters with allenoates, catalyzed by the ferrocene-modified phosphine $\mathbf{C 1}$.

Using the axially chiral spirophosphine D1, Shi and co-workers accomplished highly regioselective, diastereoselective, and enantioselective $[3+2]$ annulations of a series of alkylidene azlactones with allenoates (Scheme 18) [49]. Under mild conditions, the reactions worked efficiently to afford corresponding functionalized spirocyclic products with adjacent spiro-quaternary and tertiary stereocenters in good to excellent yields. These products were readily transformed into a variety of useful optically active amino acid analogues, including various aspartic acid derivatives.
Using the commercially available chiral catalyst $(S, S)$-EtDuphos E7, Loh and co-workers developed the asymmetric $[3+2]$ annulations of phenyl allenone and furanyl allenone with electron-deficient olefins, namely enones, maleates, and fumarates, to give corresponding functionalized cyclopentenes in moderate yields with moderate to high enantioselectivities (Scheme 19) [50]. The presence of a trimethylsilyl group at the $\alpha$-position of the allenone was key to achieving a regioselective $[3+2]$ annulation. This remarkable steric effect probably suppressed the [4+2] self-condensation of the allenone [51]. 


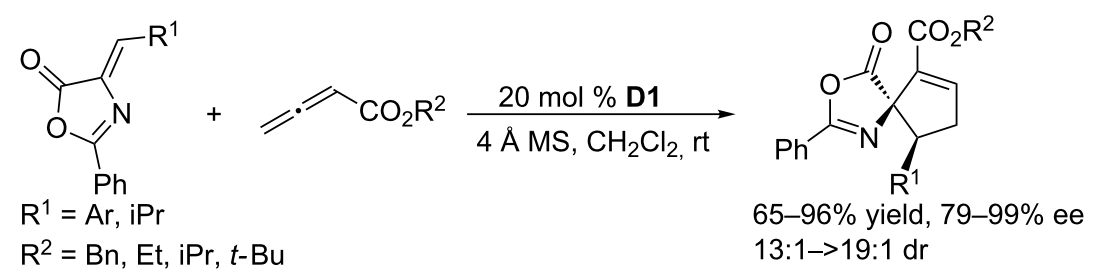

Scheme 18: Asymmetric [3 + 2] annulations of alkylidene azlactones with allenoates, catalyzed by the chiral spiro phosphine D1.

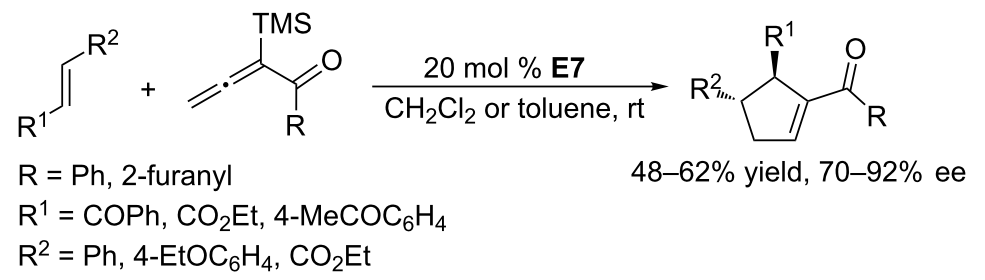

Scheme 19: Asymmetric [3 + 2] annulations of $\alpha$-trimethylsilyl allenones and electron-deficient olefins, catalyzed by the chiral phosphine E7 .

2.1.2 [3 + 2] Annulations using acyclic phosphines as chiral catalysts: In 2007, Wallace and co-workers employed the commercially available chiral phosphine $(S, S)$-DIOP F1 in asymmetric $[3+2]$ annulations of allenic ketones with a diverse array of exocyclic enones, providing a series of spirocyclic compounds - promising drug precursors - in good yields and with modest enantioselectivities (Scheme 20) [51]. Generally, it is difficult to control an enantioselective annulation when using an acyclic chiral phosphine lacking additional functionality. This example is one of the few asymmetric reactions catalyzed by an acyclic chiral phosphine.

\subsection{3 [3 + 2] Annulations using multifunctional phosphines} as chiral catalysts: In addition to cyclic chiral phosphines, multifunctional chiral phosphines can also display excellent catalytic activity and enantioselectivity in the asymmetric $[3+2]$ annulations. Through intramolecular hydrogen bonding, the bond-forming transition-state geometry between electrophile and the zwitterionic intermediate formed from the allenoate and the multifunctional chiral phosphine can be better organized, thereby delivering annulation products in high yields and ee's.

In 2007, based on their peptide catalyst studies, the Miller group developed the first $\alpha$-amino acid-based phosphine catalyst $\mathbf{H 1}$ for enantioselective $[3+2]$ annulations of allenoates with enones (Scheme 21) [52]. This catalyst performed multiple roles during the catalytic process, with the amino acid moiety providing a chiral environment and acting as a hydrogen bond donor while the phosphine unit functioned as the nucleophile. In the presence of $10 \mathrm{~mol} \%$ of $\mathbf{H 1}$, they treated both cyclic and acyclic enones with the allenoates in toluene at $-25^{\circ} \mathrm{C}$ to generate corresponding cyclopentenes as single regioisomers with high enantioselectivities. Interestingly, single amino acidbased phosphines were better than di-, tri-, and tetrapeptidebased catalysts. Of particular note, when they treated $\gamma$-substituted racemic allenoates with acyclic enones, unique dynamic kinetic asymmetric transformations occurred in the presence of

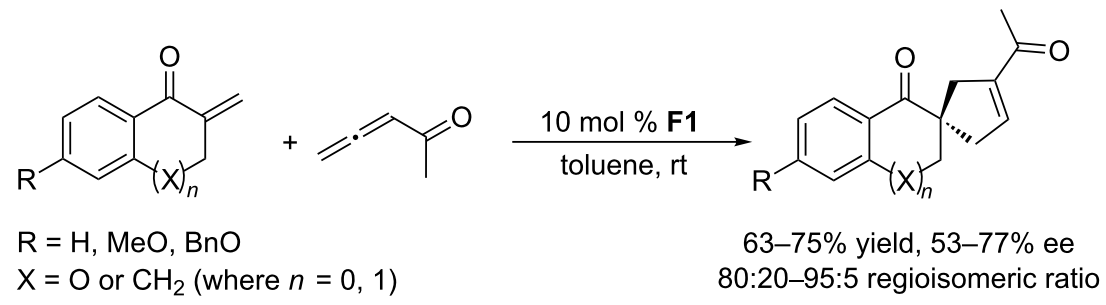


a stoichiometric amount of the catalyst $\mathbf{H 1}$, giving highly substituted cycloadducts in excellent yields as single regio- and diastereoisomers with $87-93 \%$ ee. Although a catalytic amount of H1 (20 mol \%) also afforded 93\% ee, the yield deteriorated to $38 \%$. The proposed transition-state model (Scheme 21) illustrates how the dual control of activity and stereoselectivity was achieved: through formation of a zwitterionic intermediate from the allenoate and phosphine moiety and subsequent intramolecular hydrogen bonding between the NH unit and the oxygen atom that was formerly part of the allenoate's carbonyl group.

With the idea of using a natural amino acid as the hydrogen bonding framework, Zhao and co-workers designed the simpler multifunctional chiral $\mathrm{N}$-acyl aminophosphine H5, which they readily synthesized in four steps from a commercially available Boc-protected amino alcohol [53]. With $10 \mathrm{~mol} \%$ of catalyst $\mathbf{H 5}$, various arylidenemalononitriles reacted with an allenoate in toluene at room temperature for $1 \mathrm{~h}$ to provide various chiral cyclopentenes in 79-99\% yield and 80-99\% ee (Scheme 22). In particular, the annulations of 2-cyano-3-arylacrylates, with two different electron-withdrawing functional groups, produced chiral cyclopentenes bearing adjacent quaternary and tertiary stereocenters with exclusive regioselectivity and high diastereoselectivities and enantioselectivities. That study provided a significant advance in phosphine-catalyzed $[3+2]$ annulations providing cyclopentenes. Notably, the use of $\mathrm{PPh}_{3}$ as the cata- lyst led to poor regioselectivities and moderate diastereoselectivities, revealing that the additional functional moiety was critical for accomplishing excellent enantioselectivity as well as regioselectivity and diastereoselectivity. A $\gamma$-substituted racemic allenoate also underwent the catalytic annulations smoothly through a dynamic kinetic asymmetric transformation, giving the desired products in high yields and moderate diastereoselectivities, albeit with somewhat decreased ee values. A transition-state model similar to Miller's, mentioned above, was postulated.

Attracted by the phosphine-catalyzed reactions described above, $\mathrm{Lu}$ and co-workers prepared versatile dipeptide-derived phosphines for asymmetric annulations [54]. Their multifunctional catalyst framework comprised a dipeptide moiety and a tertiary phosphine unit. In the presence of $5 \mathrm{~mol} \%$ of $\mathbf{H 1 0}$ in toluene at room temperature, the asymmetric $[3+2]$ annulations between allenoates and a series of activated olefins yielded exclusively the expected products in good to excellent yields and ee (Scheme 23) [54]. They proposed a transition state model to explain the stereoselectivity; steric hindrance between the tertbutyl group of the allenoate and the 9-phenanthryl group of the alkene suppressed the formation of the $\gamma$-isomer, affording $\alpha$-adducts as the major regioselective products, with steric shielding of the $s i$-face facilitating production of the major enantiomer (Scheme 23). Shortly after, the Lu group further

$$
\underset{\text { cyclic enones }}{\mathrm{CO}_{2} \mathrm{Bn}} \frac{10 \mathrm{~mol} \% \mathrm{H1}}{\text { toluene, }-25^{\circ} \mathrm{C}, 24-43 \mathrm{~h}} \underset{53-95 \% \text { yield, } 65-84 \% \text { ee }}{2}
$$

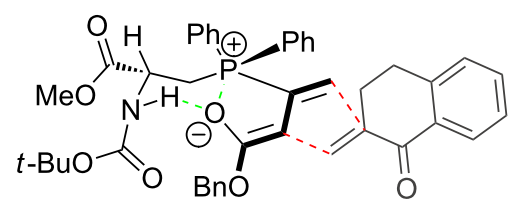

The proposed transition state (tetralone approaches from bottom)

Scheme 21: Asymmetric [3 + 2] annulations of cyclic enones with allenoates, catalyzed by the chiral $\alpha$-amino acid-based phosphine $\mathbf{H 1}$, and the proposed transition state.

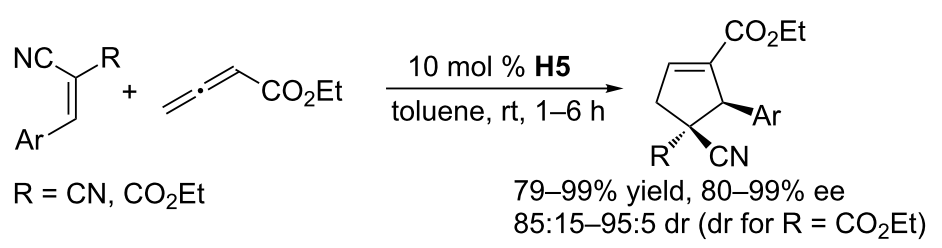




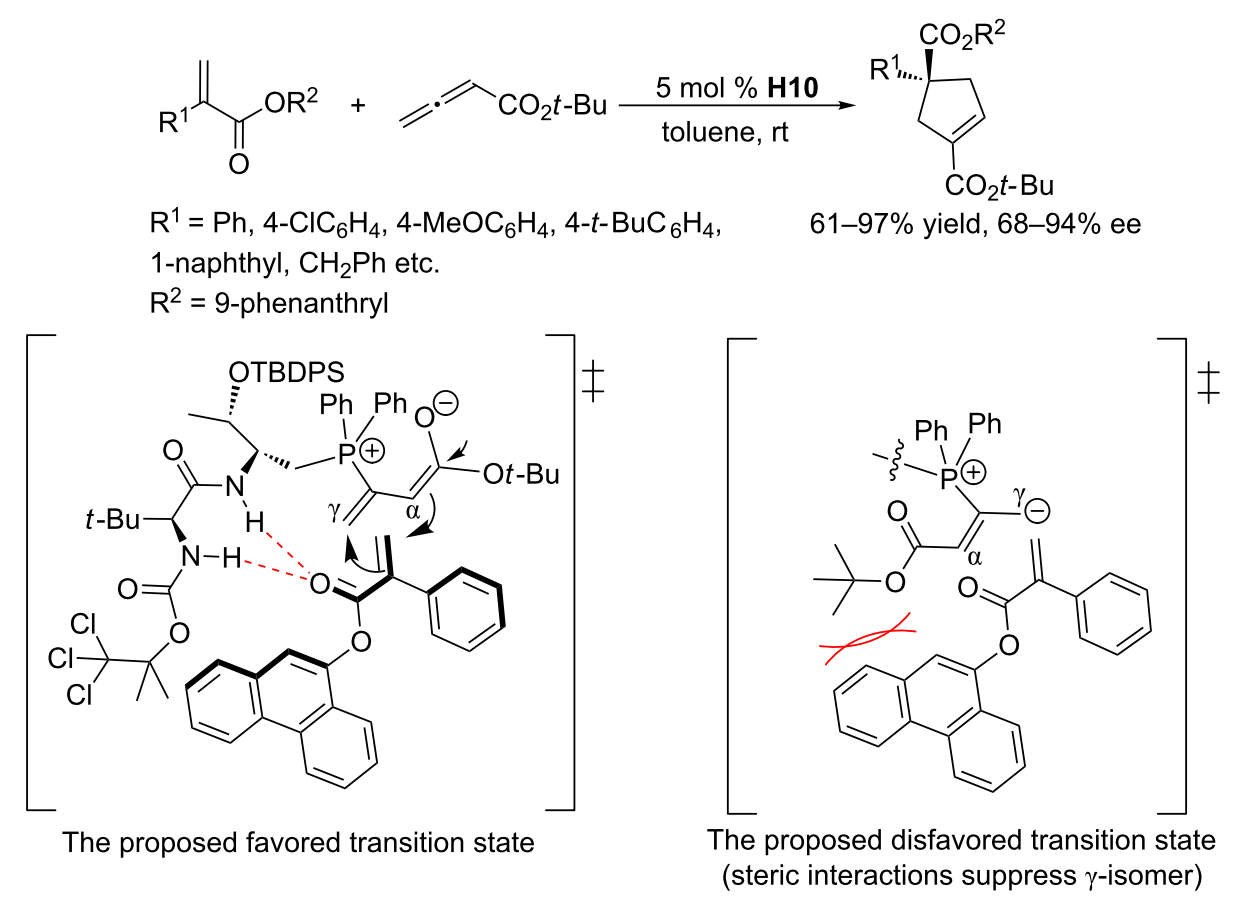

Scheme 23: Asymmetric $[3+2]$ annulations of $\alpha, \beta$-unsaturated esters with an allenoate, catalyzed by the chiral phosphine $\mathbf{H 1 0}$, and possible transition states.

expanded the substrate scope of asymmetric [3+2] annulations with allenoates to a series of 3,5-dimethyl- $1 H$-pyrazole-derived acrylamides (Scheme 24) [55]. The dipeptide-based phosphine H10 effectively promoted the reaction in good to excellent yields, albeit low to moderate enantioselectivities. In 2012, Lu, Shi, and co-workers found that the dipeptide-based phosphine H10 was also quite effective as a chiral catalyst for [3 +2$]$ annulations of various maleimides with allenoates (Scheme 25)
[56]. They obtained a wide range of bicyclic cyclopentenes in good to excellent yields. $N$-Alkyl-substituted maleimides were converted to cyclopentenes in high ee, while $N$-aryl-substituted maleimides underwent the reaction with low to moderate enantioselectivity.

Using the multifunctional chiral phosphine G6, featuring a binaphthyl skeleton and bearing a thiourea moiety, Shi and<smiles></smiles>

$\mathrm{R}=\mathrm{Me}, \mathrm{Bn}, \mathrm{Ar}$

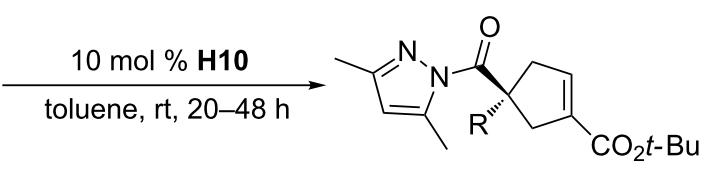

$71-93 \%$ yield, $36-66 \%$ ee

Scheme 24: Asymmetric [3 + 2] annulations of 3,5-dimethyl-1H-pyrazole-derived acrylamides with an allenoate, catalyzed by the chiral phosphine H10.

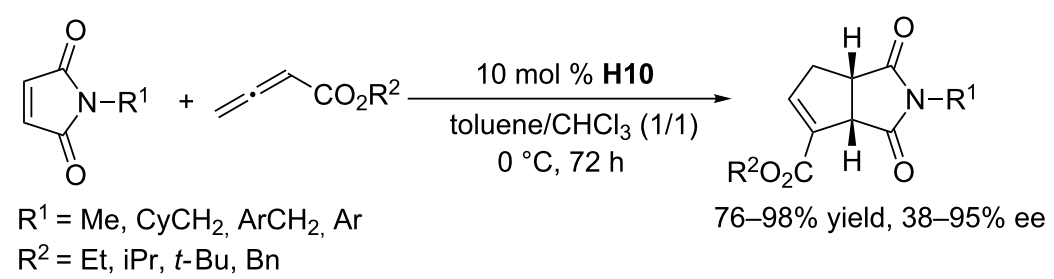


co-workers developed an asymmetric [3 +2$]$ annulation of $\alpha$-substituted acrylates with an allenoate (Scheme 26) [57]. The reactions proceeded smoothly in toluene at room temperature to give the corresponding functionalized cyclopentenes in high yields with moderate to good ee. The substrate scope was, however, very limited.

\section{$2.2[3+2]$ Annulations of allenes with activated imines}

Phosphine-catalyzed [3+2] annulation of allenes with activated imines has emerged as an important tool for the synthesis of functionalized pyrrolines, which are valuable heterocyclic compounds for the synthesis of bioactive compounds and natural products. At the end of the century, Lu and co-workers discovered the nucleophilic phosphine-catalyzed [3+2] annulation of allenes with electron-deficient imines and established a reasonable reaction mechanism [58-60]. Its asymmetric version, however, did not receive any attention for almost 10 years.

In 2006, Marinetti and co-workers reported the first asymmetric [3+2] annulations of imines with allenoates [61]. In this initial exploration, they screened various cyclic and acyclic chiral phosphines, finding that $10 \mathrm{~mol} \%$ of the acyclic chiral phosphine (S)-PHANEPHOS F3 provided the corresponding pyrroline (Scheme 27) in comparatively high ee (64\%), albeit in low yield (32\%). Other cyclic and acyclic chiral phosphines provided generally low enantioselectivities. In the same year, Gladysz and Scherer investigated the behavior of an interesting chiral rhenium-containing phosphine $\mathbf{F} 4$ in the asymmetric $[3+2]$ annulation of allenoates with $N$-tosylimines (Scheme 28) [62]. Gratifyingly, this acyclic chiral phosphine could efficiently catalyze this transformation, providing pyrroline derivatives in excellent yields (90-93\%), albeit after long reaction times ( 8 days) and with moderate ee (51-60\%).

Marinetti et al. employed the binaphthyl-based chiral cyclic phosphine $\mathbf{B 2}$ to improve the enantioselectivities of the [3+2] annulation of allenoates with $N$-tosylimines. Compared with the performance of acyclic chiral phosphines, the results were indeed improved, obtaining pyrroline products in $41-80 \%$ ee, although the enantioselectivities remained unsatisfactory (Scheme 29) [63]. In subsequent investigations of asymmetric $[3+2]$ annulations performed with $N$-diphenylphosphinoylimines (Scheme 30) and allenylphosphonates (Scheme 31) as substrates $[64,65]$, the former reactions generated pyrrolines with good ee (73-88\%), albeit with moderate yields (25-74\%)

$$
\mathrm{CH}_{2} \mathrm{NH}_{2}+\mathrm{NO}_{2} \mathrm{Bn} \frac{20 \mathrm{~mol} \% \mathrm{G6}}{\text { toluene, } \mathrm{rt}}
$$

Scheme 26: Asymmetric [3 + 2] annulations of $\alpha$-substituted acrylates with allenoate, catalyzed by the chiral phosphine $\mathbf{G 6}$.

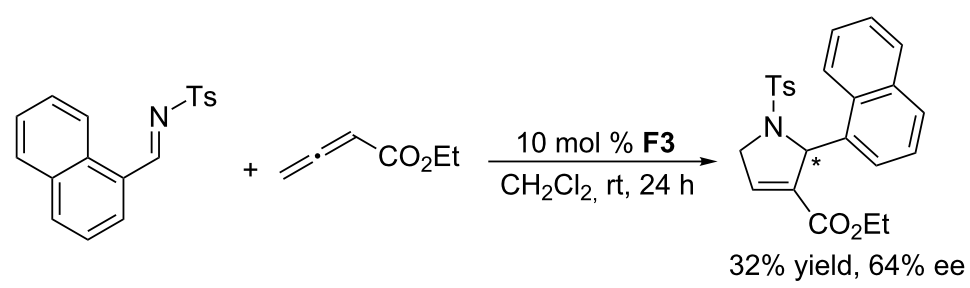

Scheme 27: Asymmetric [3+2] annulation of an $\mathrm{N}$-tosylimine with an allenoate, catalyzed by the chiral phosphine $\mathbf{F 3}$.

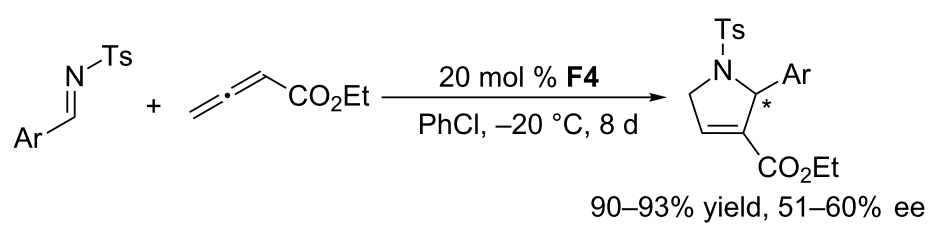




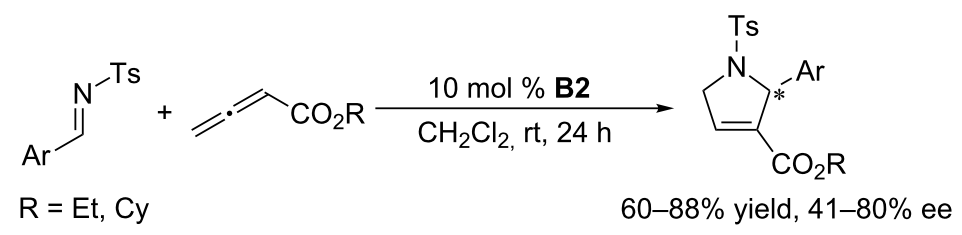

Scheme 29: Asymmetric [3 +2$]$ annulations of $N$-tosylimines with an allenoate, catalyzed by the chiral phosphine $\mathbf{B 2}$.

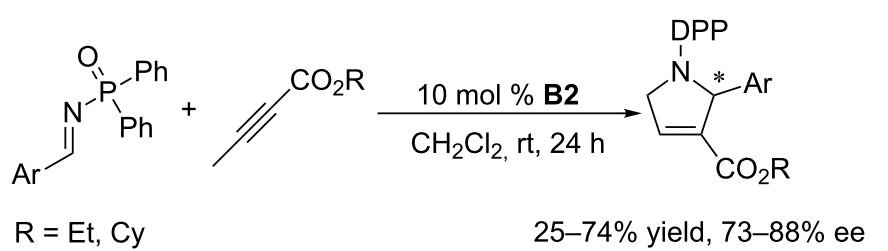

Scheme 30: Asymmetric [3 + 2] annulations of $N$-diphenylphosphinoyl aromatic imines with butynoates, catalyzed by the chiral phosphine B2.

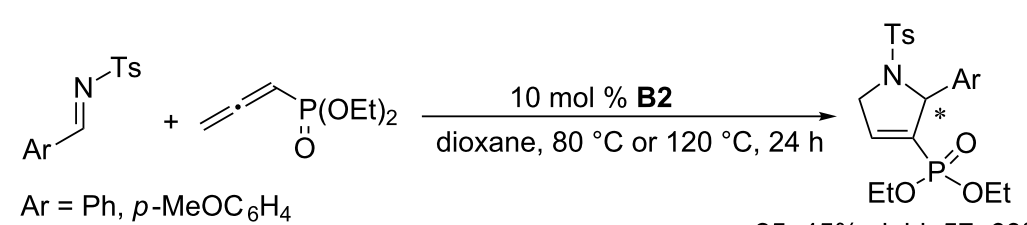

$25-45 \%$ yield, $57-68 \%$ ee

Scheme 31: Asymmetric [3 + 2] annulations of $N$-tosylimines with allenylphosphonates, catalyzed by the chiral phosphine B2.

[64]. The relative ease of removal of the diphenylphosphinoyl (DPP) protecting group makes this reaction quite valuable as an organic transformation for the preparation of secondary pyrrolines. The latter reactions (Scheme 31) required harsh conditions, leading to pyrroline derivatives in low yields with moderate ee [65]. In terms of both conversion and enantioselectivity, binaphthyl skeleton-based cyclic chiral phosphines are not ideal catalysts for asymmetric $[3+2]$ annulations of electron-deficient imines with allenes.

On the other hand, the rigid bridged [2.2.1] bicyclic chiral phosphine $\mathbf{A 3}$ appears to be an excellent catalyst for allene/imine
$[3+2]$ annulation. With a chiral phosphine-catalyzed [3+2] annulation of an indole-derived imine and an $\gamma$-ethylallenoate as the key step, Kwon and Andrews completed the first enantioselective total synthesis of the indole alkaloid (+)-ibophyllidine in 15 steps and $13 \%$ overall yield from $N$-Boc-indole-3-aldehyde (Scheme 32) [66]. This approach was the first non-formal total synthesis of a complex natural product employing phosphinecatalyzed asymmetric $[3+2]$ annulation. In the key transformation, using $10 \mathrm{~mol} \%$ of the P-chiral [2.2.1]bicyclic phosphine A3 derived from trans-L-4-hydroxyproline, asymmetric [3+2] annulation of 4-ethyl-2,3-butadienoate with an $N$-tosylaldimine (prepared in $90 \%$ yield through condensation of $p$-toluenesul-

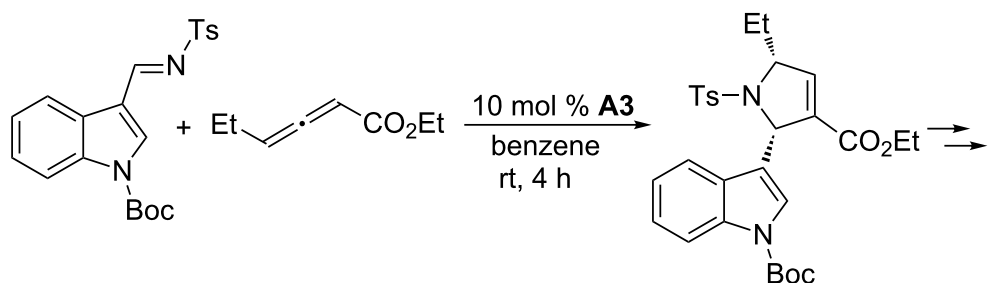

93\% yield, $99 \%$ ee

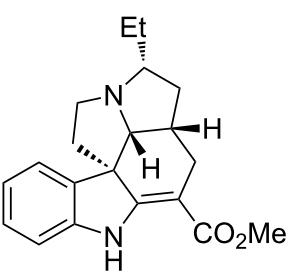

(+)-ibophyllidine

Scheme 32: Asymmetric [3 + 2] annulation of an $\mathrm{N}$-tosylimine with an allenoate, catalyzed by the chiral phosphine $\mathbf{A} 3$, and its application in the total synthesis of (+)-ibophyllidine. 
fonamide with $\mathrm{N}$-Boc-indole-3-carbaldehyde) for $4 \mathrm{~h}$ at room temperature proceeded exceedingly well, giving the desired pyrroline in $93 \%$ yield with $99 \%$ ee and high diastereoselectivity. In particular, the reaction could be performed on multigram scale to provide the optically pure pyrroline; indeed, in the presence of $10 \mathrm{~mol} \%$ of the catalyst, the annulation performed on an approximately $30 \mathrm{~g}$ scale proceeded in $94 \%$ yield and $97 \%$ ee.

By using multifunctional chiral phosphines, Jacobsen and Fang obtained a major breakthrough in development of highly enantioselective [3+2] annulations of allenoates with imines. Based on thiourea-based catalyst systems, they developed the multifunctional catalyst $\mathbf{H 3}$ containing a phosphine fragment, a thiourea moiety, and an amino acid residue [67]. In the presence of $10 \mathrm{~mol} \%$ of catalyst $\mathbf{H 3}$, with the assistance of triethylamine $(5 \mathrm{~mol} \%)$ and water $(20 \mathrm{~mol} \%)$, a wide range of $N$-diphenylphosphinoyl aromatic imines underwent cyclizations (Scheme 33) with an allenoate in toluene at $-25{ }^{\circ} \mathrm{C}$ for $48 \mathrm{~h}$, affording dihydropyrrole derivatives in $68-90 \%$ yield and excellent ee (94-98\%). The catalytic amounts of triethylamine and water significantly increased the reaction rates, facilitating proton transfer and catalyst regeneration in the reaction process. In the case of $o$-bromophenylimine, even $2.5 \mathrm{~mol} \%$ of $\mathbf{H 3}$ could deliver the corresponding product without any loss of enantioselectivity (95\% ee), albeit in slightly lower yield. Jacobsen and Fang proposed a possible transition state to explain the high enantioselectivity. In this cooperative system, the phosphine moiety was responsible for activation of the allenoate and the enantioinduction, while the thiourea unit played the dual roles of activating the imine and stereochemically controlling the association of the phosphoryl substituents of the imine. Although the accomplishments with this thiourea- based chiral catalyst were unprecedented, the substrate scope of this reaction is restricted to diphenylphosphinoyl aromatic imines because aliphatic imines decompose under the optimal conditions.

To overcome the limited substrate scope, $\mathrm{Lu}$ and co-workers explored imine-allene [3 +2$]$ annulations catalyzed by a dipeptide-derived phosphine [68]. They identified the phosphine H12, a close analogue of H10, as the most suitable catalyst. In the presence of $5 \mathrm{~mol} \%$ of $\mathbf{H 1 2}$, a wide range of alkylimines and various arylimines could be employed as reaction partners. The $[3+2]$ annulations of allenoates with $N$-diphenylphosphinoylimines proceeded smoothly in ethyl ether in the presence of $5 \AA$ molecular sieves at $0{ }^{\circ} \mathrm{C}$ within $30-60 \mathrm{~min}$, providing a variety of pyrroline derivatives in high yields with uniformly excellent enantioselectivities (Scheme 34). Chiral 2-alkylsubstituted 3-pyrrolines are highly valuable building blocks that can be further transformed into various biologically useful molecules. For example, with this reaction as a key step, a concise formal synthesis of $(+)$-trachelanthamidine was accomplished, highlighting the synthetic value of this methodology (Scheme 34).

\section{$2.3[3+2]$ Annulations of allenes with azomethine imines}

Using the chiral catalyst D4, a cyclic phosphine featuring a spiro-skeleton, Guo, Kwon, and co-workers achieved asymmetric $[3+2]$ annulation of an allenoate with an azomethine imine (Scheme 35) [69]. The reaction performed in dichloromethane at room temperature for $48 \mathrm{~h}$ afforded the product tetrahydropyrazolopyrazolone in $56 \%$ yield and $89 \%$ ee. Although only a single example was reported, their paper demonstrated that enantioselective [3+2] annulations of

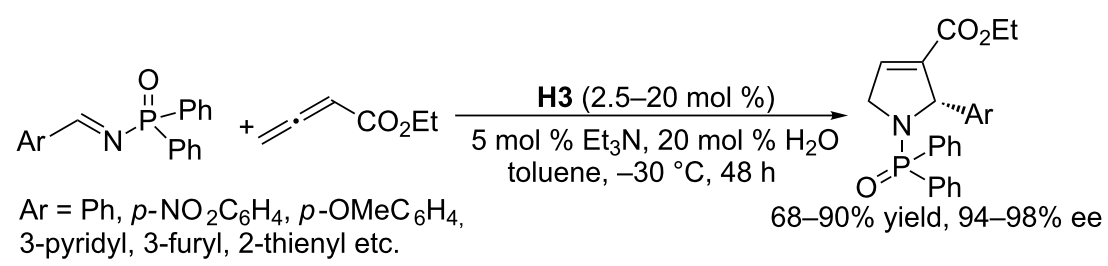
3-pyridyl, 3-furyl, 2-thienyl etc.

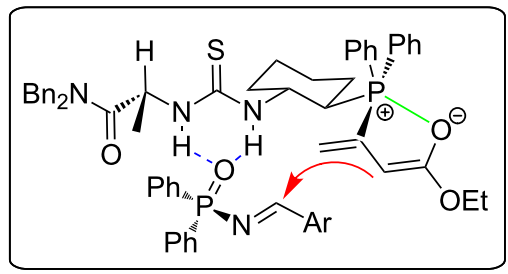




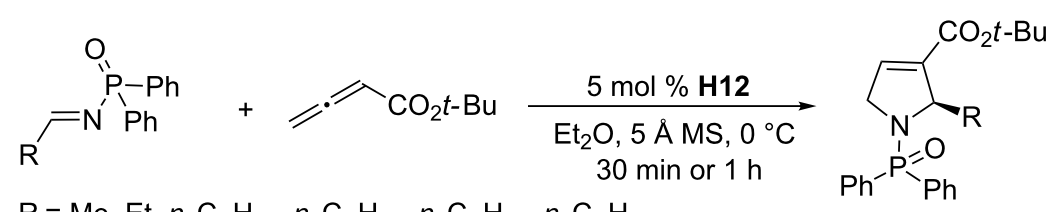

$\mathrm{R}=\mathrm{Me}, \mathrm{Et}, n-\mathrm{C}_{5} \mathrm{H}_{11}, n-\mathrm{C}_{6} \mathrm{H}_{13}, n-\mathrm{C}_{7} \mathrm{H}_{15}, n-\mathrm{C}_{8} \mathrm{H}_{17}$,

$75-94 \%$ yield, $93-99 \%$ ee $\mathrm{Ph}\left(\mathrm{CH}_{2}\right)_{2}$, iPr, iBu, Cy, styryl, $\mathrm{Ph}, 4-\mathrm{BrC}_{6} \mathrm{H}_{4}, 3-\mathrm{BrC}_{6} \mathrm{H}_{4}$, 4$\mathrm{MeOC}_{6} \mathrm{H}_{4}$, 3- $\mathrm{CNC}_{6} \mathrm{H}_{4}$, 2-naphthyl, 2-furyl, 2-thienyl<smiles>CC(C)(C)OCC=C=C[CH+]CCOS(=O)(=O)c1ccccc1</smiles>

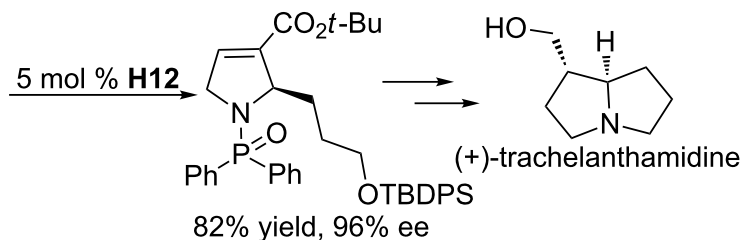

Scheme 34: Asymmetric [3+2] annulation of $\mathrm{N}$-diphenylphosphinoylimines with allenoates, catalyzed by the chiral phosphine $\mathbf{H} 12$, and its application in the formal synthesis of $(+)$-trachelanthamidine.

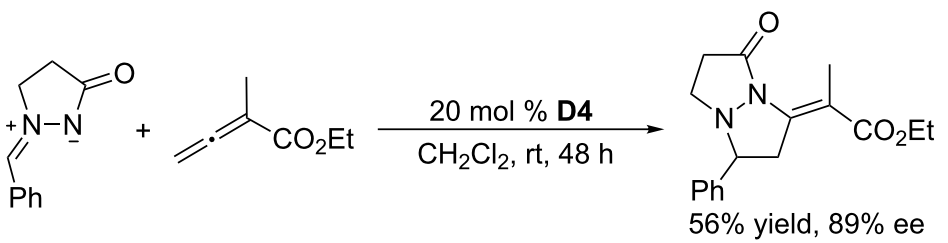

Scheme 35: Asymmetric [3 +2$]$ annulation of an azomethine imine with an allenoate, catalyzed by the chiral phosphine D4

allenoates with azomethine imines could be accomplished when using a suitable chiral catalyst.

\section{$2.4[3+2]$ Annulations of alkynes with activated alkenes}

In addition to allenoates, alkynes are also compatible substrates for asymmetric $[3+2]$ annulations with activated alkenes. Using the commercially available chiral catalyst $(R, R)$ DIPAMP F2, 3-butynoates underwent [3 +2$]$ annulations with electron-deficient olefins, providing highly functionalized cyclopentenes in $66-95 \%$ yield with $81-99 \%$ ee (Scheme 36 ) [70]. Interestingly, this acyclic catalyst proved to be remarkably efficient at mediating these tandem reactions, despite its structure being less rigid than most of aforementioned cyclic chiral phosphines. Control experiments indicated that under phosphine catalysis conditions, 3-butynoate initially isomerized to the allenoate, which subsequently underwent [3+2] annulations with activated alkenes. Notably, only $10 \mathrm{~mol} \%$ of catalyst F2 was required, even though it was responsible for promoting the two proposed steps.

\section{5 [3 + 2] Annulations of $\mathrm{MBH}$ carbonates with acti- vated alkenes}

$\mathrm{MBH}$ carbonates, which are readily accessible from the adducts of MBH reactions, have been used extensively in organocatalysis for the formation of $\mathrm{C}-\mathrm{C}$ and $\mathrm{C}-$ heteroatom bonds $[71,72]$.

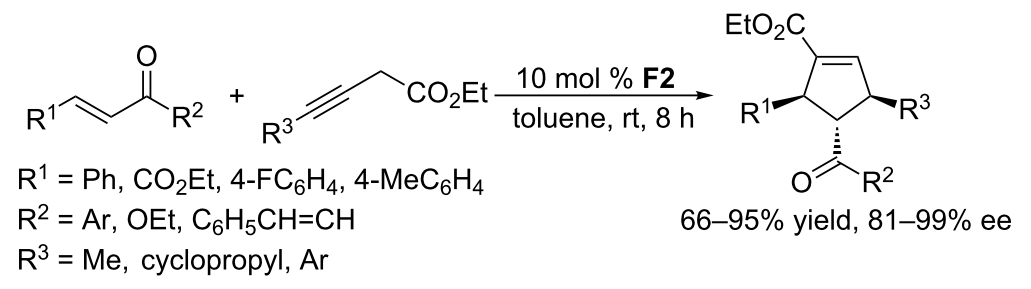


In addition to activated allenes and alkynes, MBH carbonates are often employed as versatile substrates for the phosphinecatalyzed annulations.

In 2010, using the cyclic phosphine (S)-DMM-SITCP D3, Tang and Zhou developed an intramolecular asymmetric $[3+2]$ annulation by combining MBH carbonates and electron-deficient alkenes into a single molecule (Scheme 37) [73]. In the presence of $10 \mathrm{~mol} \%$ of D3, a variety of $\alpha, \beta$-unsaturated carbonyl compounds were transformed efficiently in toluene at $-5{ }^{\circ} \mathrm{C}$ to give optically active benzobicyclo[4.3.0] compounds 5 in excellent yields with high enantioselectivities (77-95\% ee). Interestingly, the addition of $20 \mathrm{~mol} \%$ of $\mathrm{Ti}(\mathrm{O}-\mathrm{iPr})_{4}$, under otherwise identical conditions, inhibited the isomerization process, causing the benzobicyclo[4.3.0] compounds 6 to be obtained as major products in excellent yields with high enantioselectivities $(77-92 \%$ ee).

In 2011, using the chiral phosphine (+)-Ph-BPE E1 as the catalyst, Barbas and co-workers achieved asymmetric [3+2] annulations of $\mathrm{MBH}$ carbonates with methyleneindolinones (Scheme 38) [74]. In the presence of $10 \mathrm{~mol} \%$ of this catalyst,

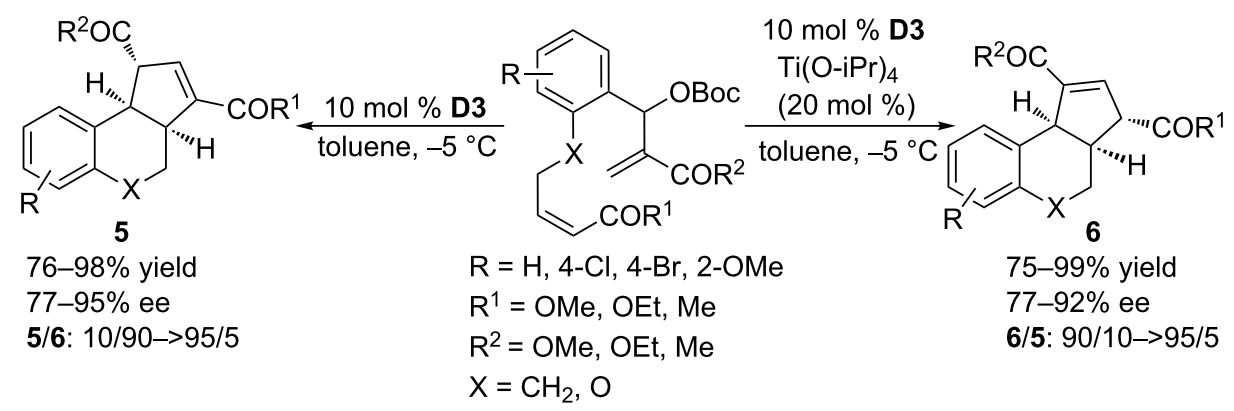

Scheme 37: Asymmetric intramolecular [3 + 2] annulations of electron-deficient alkenes and MBH carbonates, catalyzed by the chiral phosphine D3.

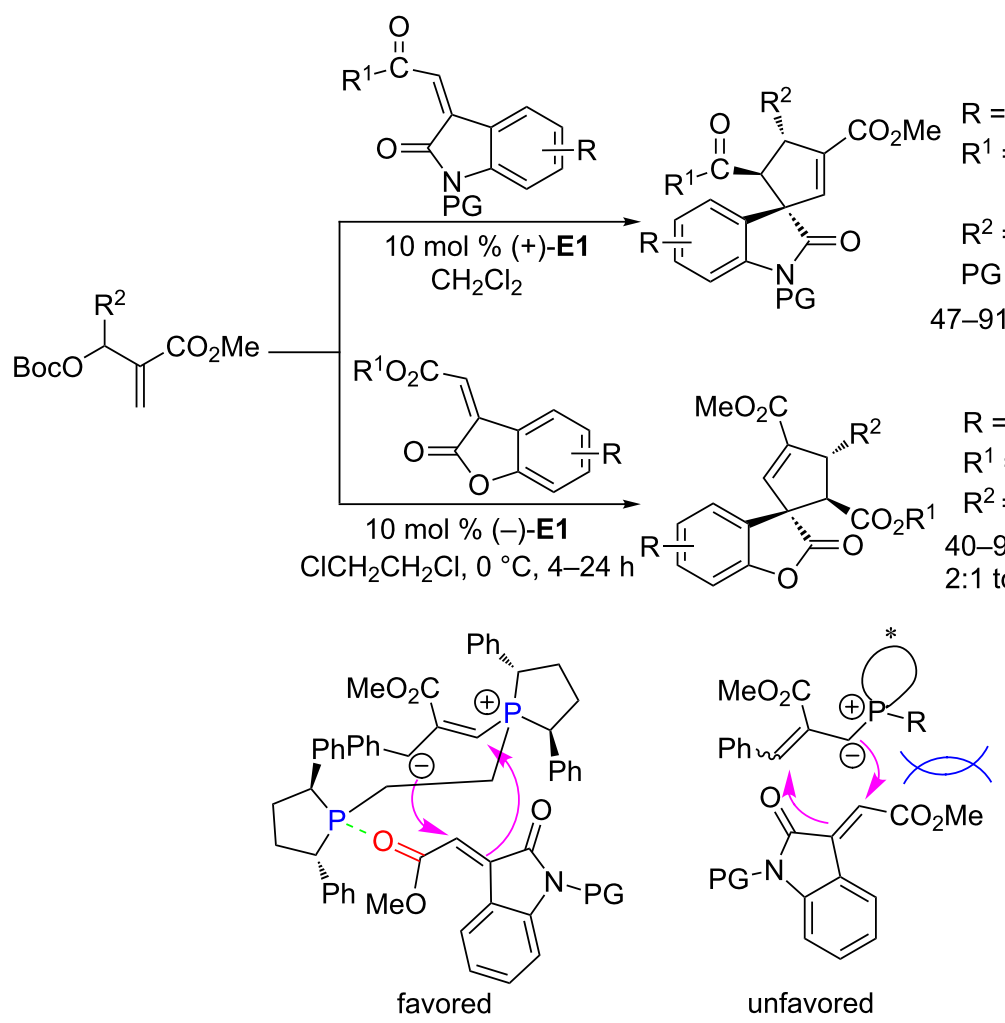

Scheme 38: Asymmetric [3 + 2] annulations of methyleneindolinone and methylenebenzofuranone derivatives with MHB carbonates, catalyzed by the chiral phosphines (+)-E1 and (-)-E1, and possible transition states. 
the reaction proceeded well in dichloromethane to furnish a wide range of spirocyclopenteneoxindoles in moderate to excellent yields and ee's (Scheme 38). The yields and stereoselectivities were significantly influenced not by electronic effects but by aromatic interactions. Aryl-substituted MBH carbonates reacted smoothly to afford polyfunctionalized spirocyclopenteneoxindoles in good yields $(63-85 \%)$ and with excellent enantioselectivities (91-99\% ee). In contrast, the ee was fairly low (46\%) when using a methyl-substituted MHB carbonate at the allylic site. It was rationalized that the aromatic $\pi-\pi$ interactions between the catalyst and the substrates favored the formation of the products. Based on control experiments and aforementioned results, Barbas and co-workers proposed a plausible mechanism and suggested that the high stereoselectivity resulted from steric interactions between the bulky substituent of the phosphonium ylide from the $\mathrm{MBH}$ carbonate and the carboxylic ester of methyleneindolinone shielding one possible attacking face during the nucleophilic attack (Scheme 38). In 2013, using the same catalytic system, Barbas and co-workers further developed highly stereoselective phosphine-catalyzed $[3+2]$ annulations of MBH carbonates with methylenebenzofuranone derivatives, constructing a variety of complex polysubstituted spirocyclopentenebenzofuranones in high yields with good to excellent enantioselectivities [75].

Using the amino acid-derived chiral phosphine $\mathbf{H 2}, \mathrm{Lu}$ and co-workers explored asymmetric [3+2] cycloadditions between MBH carbonates and activated isatin-based alkenes (Scheme 39) [76]. The reactions, performed in chloroform in the presence of molecular sieves at room temperature, provided biologically important 3-spirocyclopentene-2-oxindoles with two contiguous quaternary centers in very high yields and with good enantioselectivities; they tolerated a wide range of $\mathrm{MBH}$ carbonates featuring different electronic properties for their aromatic and heteroaromatic moieties at the allylic position (e.g., phenyl, 4-cyanophenyl, 4-methylphenyl, 2-naphthyl, 3 -furyl) as well as diverse isatin-derived alkenes having substituents on their phenyl rings. Of particular interest, even the relatively inert $\mathrm{MBH}$ adduct presenting an alkyl unit at the allylic position was applicable to the reactions, furnishing the corresponding product in good yield and enantioselectivity, albeit lower regioselectivity (1:2). After studying the substrate scope and limitations, $\mathrm{Lu}$ and co-workers proved that these reactions could be performed in a convenient one-pot manner. For example, the one-pot reactions of isatins, malononitriles (precursors of activated alkene), and $\mathrm{MBH}$ adducts produced corresponding spirooxindoles with the same enantioselectivity as that between activated alkenes and MBH adducts, albeit in slightly diminished yields. Shi and co-workers also studied this reaction, but using the chiral bifunctional thiourea-phosphine catalyst G7. The [3 + 2] annulation of MBH carbonate with an activated isatin-based alkene in toluene at room temperature gave the corresponding $\gamma$-cycloadduct as the major product in $92 \%$ yield, with 9:1 dr and $74 \%$ ee [77].

Using the amino acid-derived chiral phosphine catalyst H11, Lu and co-workers performed asymmetric $[3+2]$ annulations between MBH carbonates and maleimides, obtaining access to a wide range of bicyclic imides in excellent yields and enantioselectivities and high diastereoselectivities (Scheme 40) [78]. This methodology worked very well even when operated on gram-scale.

In 2012, using multifunctional chiral phosphines as catalysts, Shi and co-workers investigated a range of asymmetric [3 + 2] annulations of $\mathrm{MBH}$ carbonates with various activated alkenes

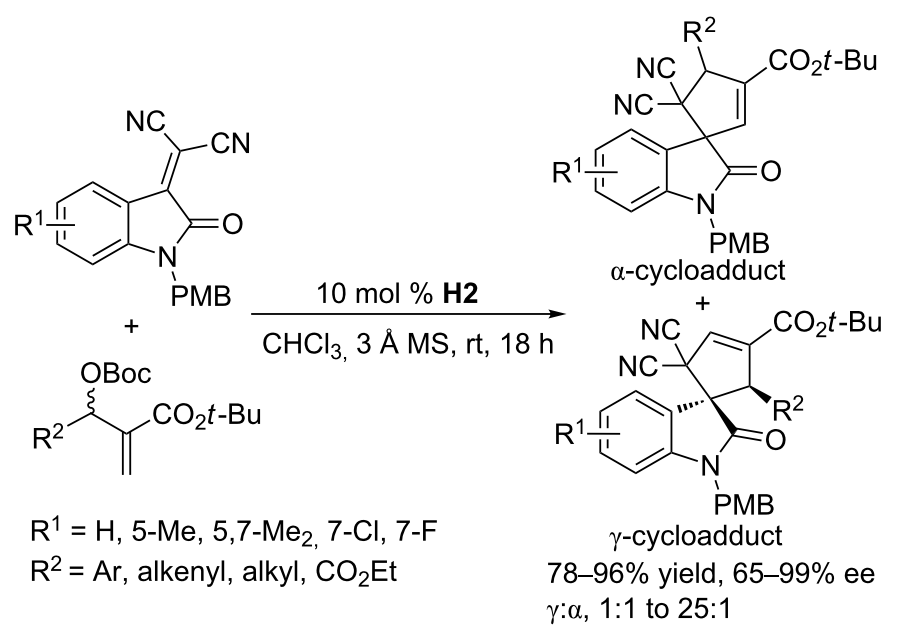

Scheme 39: Asymmetric [3 + 2] annulations of activated isatin-based alkenes with MBH carbonates, catalyzed by the chiral phosphine $\mathbf{H 2}$. 


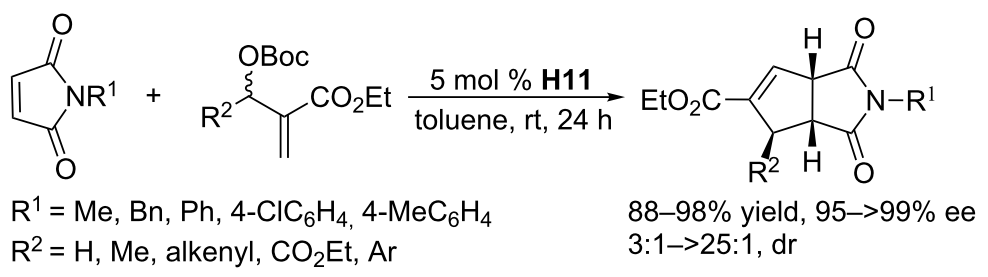

Scheme 40: Asymmetric [3 + 2] annulations of maleimides with MBH carbonates, catalyzed by the chiral phosphine H11.

(Scheme 41). They synthesized a range of multifunctional thiourea-phosphines, among which the chiral phosphine $\mathbf{H 4}$ proved to be a versatile and powerful catalyst for these asymmetric [3+2] annulations. In the presence of $20 \mathrm{~mol} \%$ of this chiral phosphine, various activated alkenes, including maleimides [79], trifluoroethylidenemalonate [80], and 2-arylideneindane-1,3-diones [81], were highly compatible for asymmetric $[3+2]$ annulation reactions with $\mathrm{MBH}$ carbonates, providing moderate to excellent yields, diastereoselectivities, and enantioselectivities (Scheme 41). An array of substituted $\mathrm{MBH}$ carbonates bearing neutral, electron-withdrawing, and electron-donating aromatic groups were effectively converted to the corresponding functionalized cyclopentenes. Nevertheless, $\mathrm{MBH}$ carbonates having aliphatic substituents, rather than aromatic ones, at the allylic position were not tolerated in these transformations.

\section{$2.6[3+2]$ Annulations of an alkyne with isatins}

Using the acyclic chiral phosphine $(4 S, 5 S)$-DIOP F1, Shi and co-workers developed asymmetric [3+2] annulations of but-3yn-2-one with $\mathrm{N}$-protected isatins (Scheme 42) [82]. In the presence of $20 \mathrm{~mol} \%$ of F1, but-3-yn-2-one reacted with a series of

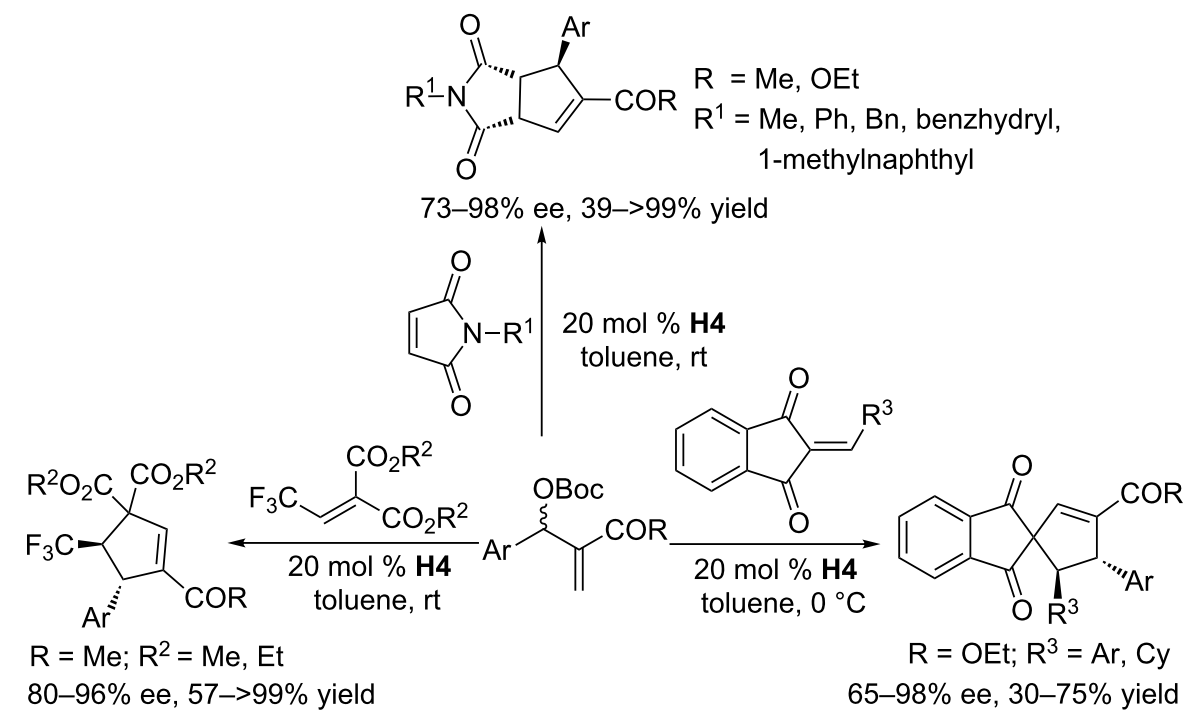

Scheme 41: A series of [3+2] annulations of various activated alkenes with MBH carbonates, catalyzed by the chiral phosphine $\mathbf{H 4}$.

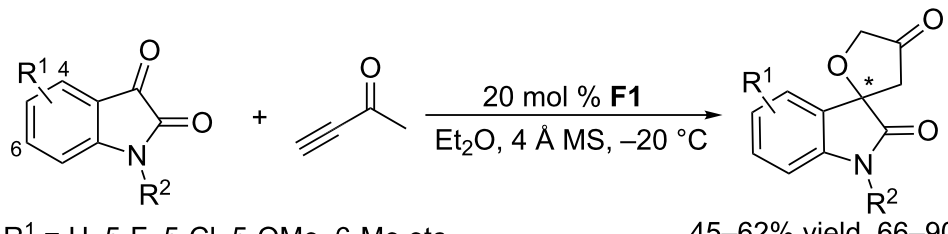

$\mathrm{R}^{1}=\mathrm{H}, 5-\mathrm{F}, 5-\mathrm{Cl}, 5-\mathrm{OMe}, 6-\mathrm{Me}$ etc

$45-62 \%$ yield, $66-90 \%$ ee

$\mathrm{R}^{2}=\mathrm{Bn}$, allyl, Me, anthracenemethyl 
$\mathrm{N}$-protected isatins in ethyl ether at $-20{ }^{\circ} \mathrm{C}$ to afford enantioenriched spiro[furan-2,3'-indoline]-2',4(5H)-diones with good to excellent ee's, albeit moderate yields.

\section{$2.7[4+2]$ Annulations of allenes with activated imines}

Compared with phosphine-catalyzed asymmetric [3+2] annulations, asymmetric [4+2] annulations have been less studied, with only limited examples reported. In 2005, based on Kwon's phosphine-catalyzed [4 2] annulation of allenoates with $\mathrm{N}$-tosylimines [83], Fu and co-workers developed an asymmetric variant using the binaphthyl-based chiral cyclic phosphine B1 (Scheme 43) [84]. In the presence of $5 \mathrm{~mol} \%$ of B1, asymmetric $[4+2]$ annulations of allenoates with a broad range of aromatic $\mathrm{N}$-tosylimines worked efficiently in dichloromethane at room temperature to give an array of chiral piperidine derivatives in good to excellent stereoselectivities (up to $99 \%$ ee, up to $99: 1 \mathrm{dr}$ ) and moderate to excellent yields (42-99\%). The piperidine products could be transformed conveniently into biologically important heterocyclic compounds. For example, with this asymmetric $[4+2]$ annulation as the key step, using indole-2-carboxaldehyde as the starting material, the bridged tetracyclic framework of the Alstonia class of indole alkaloids was readily formed in high yield. This asymmetric $[4+2]$ annulation was a seminal advance in the area of nucleophilic phosphine catalysis, attracting much attention toward chiral phosphine-catalyzed asymmetric reactions.

Using the bifunctional $N$-acylaminophosphine H5, Zhao and co-workers also achieved enantioselective [4 +2] annulations of allenoates with $N$-tosylaldimines (Scheme 44) [85]. In the pres- ence of $4 \AA$ molecular sieves and with $\mathrm{PhCF}_{3}$ and $\mathrm{CH}_{2} \mathrm{Cl}_{2}$ as the mixed solvent, H5-catalzyed enantioselective [4 + 2] annulations between $\alpha$-substituted allenoates and $N$-tosylaldimines afforded a wide range of tetrahydropyridines in high yields and with good to excellent enantioselectivities. For some imines, the bifunctional phosphine displayed catalytic capability superior to that of Fu's monophosphine system [84] in terms of yield, ee, or both. Based on previous literature, Zhao and co-workers speculated two possible transition states; in both cases, the dienolate adopts a conformation, featuring hydrogen bonding and $\mathrm{O}-\mathrm{P}$ electrostatic attraction, that favors $r e$-face attack of the imine (Scheme 44).

\section{$2.8[4+2]$ Annulations of allenes with activated alkenes}

Phosphine-catalyzed [4 + 2] annulation of an allenoate with an activated alkene is a powerful tool for the synthesis of a functionalized cyclohexene [86,87]. To develop an asymmetric version, $\mathrm{Lu}$ and co-workers screened 14 bifunctional chiral amino acid-derived phosphines, from which they found that the amido phosphine $\mathbf{H 1 3}$ was the most efficient catalyst for the $[4+2]$ annulations of allenoates with 2-aryl-1,1-dicyanoethylenes (Scheme 45) [88]. In the presence of $10 \mathrm{~mol} \%$ of $\mathbf{H 1 3}$ in THF at room temperature, the 1,1-dicyanoethylenes reacted with the $\alpha$-substituted allenoates to afford an array of functionalized cyclohexenes. A wide range of 2-aryl- and 2-heteroaryl1,1-dicyanoethylenes were applicable to this transformation, rendering high yields, moderate to good diastereoselectivities, and excellent enantioselectivities. These reaction conditions were not applicable, however, to transformations involving isatin-derived alkenes as substrates, resulting in very poor dia-
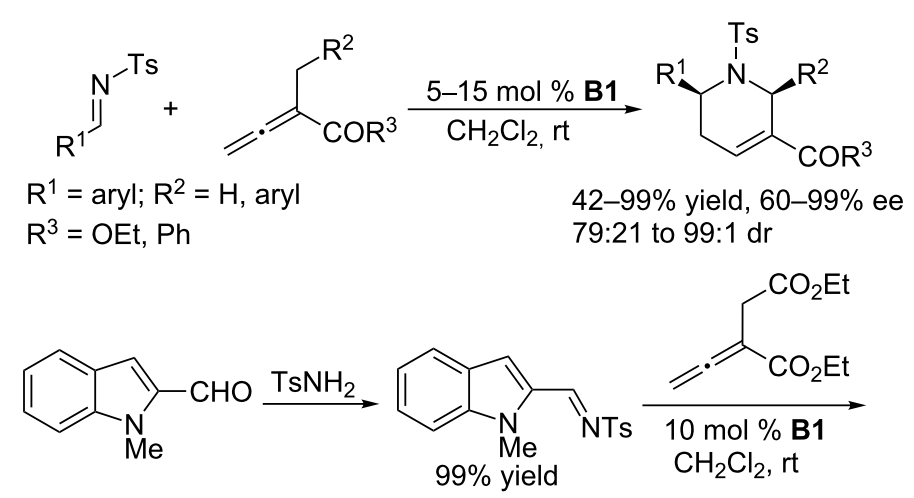

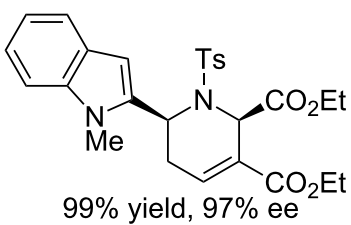

93:7 dr

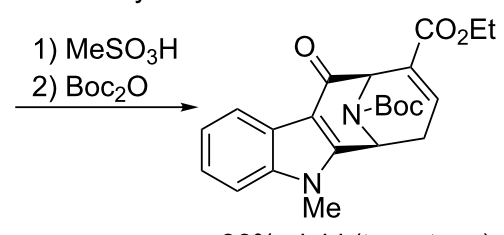

$86 \%$ yield (two steps) 


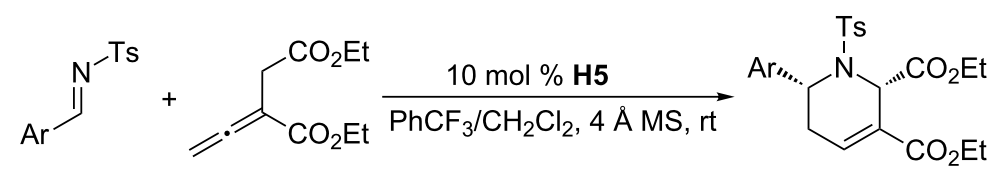

$\mathrm{Ar}=\mathrm{Ph}, 4-\mathrm{MeOC}_{6} \mathrm{H}_{4}, 3-\mathrm{FC}_{6} \mathrm{H}_{4}$, 2-thienyl, etc. $\quad \begin{aligned} & 66-98 \% \text { yield, } 82-96 \% \text { ee } \\ & 4: 1-16: 1 \mathrm{dr}\end{aligned}$

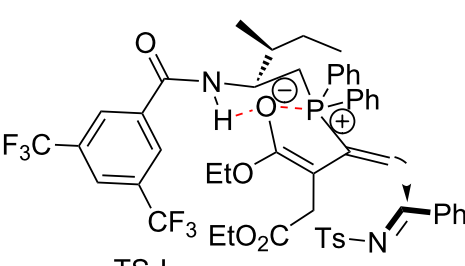

TS-I

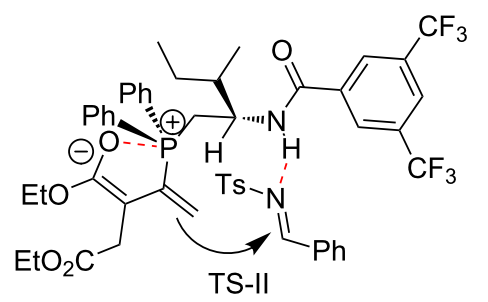

Scheme 44: Asymmetric [4 + 2] annulations catalyzed by the chiral phosphine $\mathbf{H 5}$.<smiles>COC(=O)C1=CC[C@@H]([Al])C(C#N)(C#N)C1C(=O)OC</smiles><smiles>C=C/C(C#N)=C\[Mg]</smiles>
THF, rt

$\mathrm{Ar}=\mathrm{Ph}, 4-\mathrm{MeOC}_{6} \mathrm{H}_{4}, 4-\mathrm{FC}_{6} \mathrm{H}_{4}$, 2-ethynyl- $\mathrm{C}_{6} \mathrm{H}_{4}, 2$-furyl, etc. $85-96 \%$ yield, $91-99 \%$ ee $60: 40-87: 13 \mathrm{dr}$<smiles>C=C=C(CC(=O)OC)C(=O)OC</smiles>

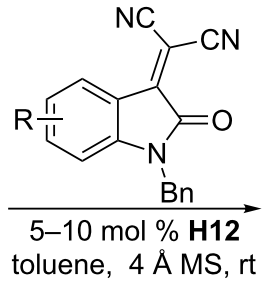

$\mathrm{R}=\mathrm{H}, 5-\mathrm{Me}, 5-\mathrm{F}, 5-\mathrm{MeO}$, etc $89-96 \%$ yield, $89-93 \%$ ee 95:5-99:1 dr

Scheme 45: Asymmetric [4 + 2] annulations catalyzed by the chiral phosphines $\mathbf{H} 13$ and $\mathbf{H} 12$.

stereoselectivities and enantioselectivities. For these oxindole derivatives, the use of the chiral dipeptide-derived phosphine H12 in toluene at room temperature provided the corresponding $[4+2]$ cycloadducts, 3 -spirocyclohexene-2-oxindoles, in high yields with excellent ee and dr. These asymmetric $[4+2]$ annulations of allenoates with activated alkenes significantly offset the limitations of Diels-Alder reactions when synthesizing enantioenriched multisubstituted cyclohexenes.
At about the same time, Zhao and co-workers also examined the application of bifunctional chiral phosphines in asymmetric $[4+2]$ annulations between activated alkenes and $\alpha$-substituted allenoates (Scheme 46) [89]. They found that the chiral $N$-acyl aminophosphine $\mathbf{H 6}$ in 1,2-dichloroethane at $-18{ }^{\circ} \mathrm{C}$ mediated a smooth reaction to produce various optically active cyclohexenes containing three neighboring carbon stereocenters in high yields and with excellent ee. Notably, not only arylidenecyanoacetates but also alkylidenecyanoacetates (e.g., isobutyli-

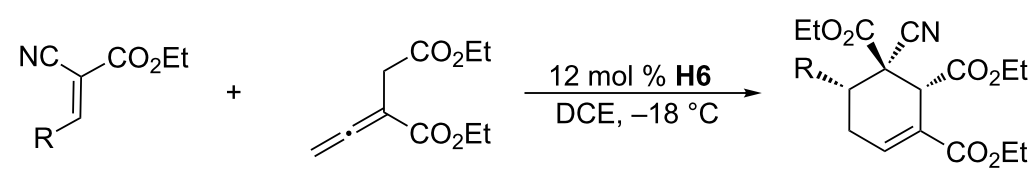

$\mathrm{R}=\mathrm{iPr}, \mathrm{Ph}, 4-\mathrm{MeOC}_{6} \mathrm{H}_{4}$, 2-thienyl, piperonyl, etc. 
denecyanoacetate) were applicable to the reaction, being converted to their desired products in excellent yields and ee.

\section{9 [2 + 2] Annulations of ketenes with imines}

Various ketenes, another class of cumulenes that are analogues of allenes, are also suitable substrates for phosphine-catalyzed asymmetric annulations. Unlike allenes, which act as three- and four-carbon synthons, ketenes typically serve as binary synthons in their annulations. Recently, using the cyclic chiral phosphine ( $R$ )-BINAPHANE B7, the Kerrigan group developed phosphine-catalyzed asymmetric $[2+2]$ annulations of ketenes with imines (Scheme 47) [90]. In the presence of $10 \mathrm{~mol} \%$ of $\mathbf{B} 7$ in dichloromethane or tetrahydrofuran, the reaction of disubstituted ketenes and $N$-tosyl arylimines provided corresponding trans- $\beta$-lactams in moderate to excellent ee (up to 98\%), diastereoselectivities (up to 99:1 dr), and yields (up to $>99 \%$ ). Of particular interest, this methodology facilitates the formation of diverse trans- $\beta$-lactams that are complimentary to the related cis-lactams.

\subsection{0 [4 + 1] Annulations of MBH carbonates with dienes}

Phosphine-catalyzed asymmetric $[4+1]$ annulations between MBH carbonates and activated dienes could be achieved when using the bifunctional phosphine $\mathbf{G 6}$ as the catalyst (Scheme 48) [91]. The reaction worked efficiently in the presence of $4 \AA$ molecular sieves in toluene at room temperature to furnish a variety of functionalized cyclopentenes bearing quaternary carbon stereocenters in $29-92 \%$ yield with 66-98\% ee. Unfortunately, the reaction times were long (up to 7 days), and substrates with bulky substituents were not well tolerated, giving low yields or ee. Notably, the reactions proved that $\mathrm{MBH}$

carbonates can serve as one-carbon synthons for the annulations and expanded the utility of $\mathrm{MBH}$ carbonates in synthetic chemistry.

\subsection{Annulations through homodimerization of ketoketenes}

Using the chiral catalysts ( $S, R \mathrm{p})$-Josiphos F5 and F6, the Kerrigan group developed the asymmetric homodimerization of ketenes (Scheme 49) [92]. This self-condensation of ketoketenes proceeded in dichloromethane at $-25{ }^{\circ} \mathrm{C}$ to give chiral $\beta$-lactones in high yields (up to $99 \%$ ) with good to excellent ee (up to $96 \%$ ). In subsequent transformations, the $\beta$-lactone products underwent various ring opening reactions to provide very useful derivatives, such as 1,3-diketones and enol esters, with good diastereoselectivity.

$$
=\overbrace{R^{2}}^{\stackrel{10 \mathrm{~mol}^{2} \% \mathbf{F} 5 \text { or } \mathrm{F} 6}{\mathrm{CH}_{2} \mathrm{Cl}_{2},-25^{\circ} \mathrm{C}}}
$$

$\mathrm{R}^{1}=\mathrm{Ph}$, 4-tolyl, 3-thienyl, etc.

$\mathrm{R}^{2}=\mathrm{Me}, \mathrm{Et}, n-\mathrm{Bu}$

Scheme 49: Asymmetric homodimerization of ketenes, catalyzed by the chiral phosphine $\mathbf{F 5}$ and $\mathbf{F 6 .}$

\subsection{Annulations through domino aza-MBH/Michael reactions}

Because organocatalytic asymmetric domino reactions allow the rapid construction of structurally complex molecules from readily available starting materials in two or more steps in a single operation, they have attracted much attention. Bifunc-

$$
\begin{aligned}
& \mathrm{R}^{1} \\
& \mathrm{R}^{1}=\mathrm{Ph}, 2-\mathrm{FC}_{6} \mathrm{H}_{4}, 4-\mathrm{MeOC}_{6} \mathrm{H}_{4}, 4-\mathrm{NO}_{2} \mathrm{C}_{6} \mathrm{H}_{4} \text {, etc. } \\
& \mathrm{R}^{2}=\mathrm{Me}, \mathrm{Et}, \mathrm{Ph}, \mathrm{PPr}, \mathrm{Cy} \\
& \mathrm{R}^{3}=\mathrm{Me}, \mathrm{Et}, n-\mathrm{Bu}
\end{aligned}
$$

Scheme 47: Kerrigan's [2 + 2] annulations of ketenes with imines, catalyzed by the chiral phosphine B7.

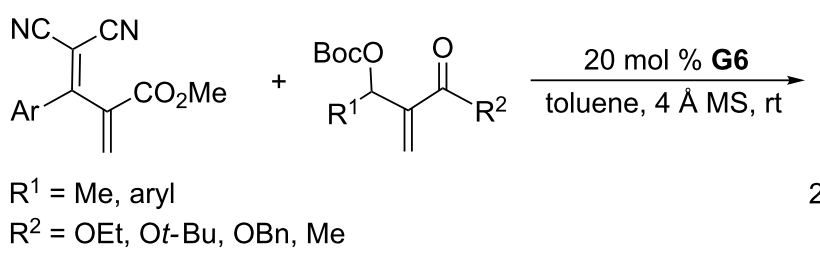

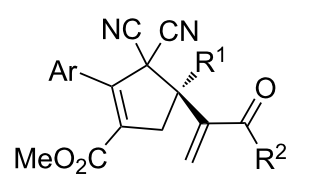

$29-92 \%$ yield, $66-98 \%$ ee 
tional chiral phosphines are ideal chiral catalysts for tandem reactions. In 2010, using the bifunctional chiral phosphine G1, bearing both Brønsted acid and Lewis base units, as the catalyst, asymmetric domino aza-MBH/aza-Michael reactions of activated alkenes and $N$-tosylimines with Michael acceptor moieties at their ortho positions were accomplished to give chiral 1,3-disubstituted isoindolines (Scheme 50) [93]. Good to excellent yields were obtained with excellent ee. A wide range of activated alkenes containing acyl, alkoxycarbonyl, and formyl groups and a series of $N$-tosylarylimines with alkyl- and halo-substituted benzene rings were compatible with the reaction conditions. The obtained products could be transformed smoothly into many complex and potentially useful compounds, through diverse derivatization, without significant losses of enantiomeric excesses.

\subsection{Annulations through tandem RC/Michael reac- tions}

In 2012, using the chiral threonine-derived phosphine H14,

Zhong and Loh developed asymmetric [4 +2$]$ annulations of activated $N$-sulfonyl-1-aza-1,3-dienes and alkenes through tandem RC/Michael reactions (Scheme 51) [94]. In the presence of $10 \mathrm{~mol} \%$ of H14, various 1-aza-1,3-dienes smoothly underwent $[4+2]$ annulations with enones in chloroform at room temperature, affording a broad spectrum of densely functionalized tetrahydropyridine derivatives, with exclusive 4,5trans diastereoselectivity, excellent enantioselectivity, and good to excellent yields. The transformations tolerated a wide range of $N$-sulfonyl-1-aza-1,3-dienes with different $\mathrm{C} 4$-substituents, both aryl and alkyl. The addition of a Brønsted acid to the reaction system slightly improved the yields and diastereocontrol. In addition, the resulting tetrahydropyridines could be transformed to more complex dihydroxylated piperidine derivatives.

At almost the same time, an intramolecular variant of this $[4+2]$ annulation was developed, employing the chiral bifunctional phosphine $\mathbf{H 1 5}$ as the catalyst (Scheme 52) [95]. The substrates were constructed by installing an acrylate moiety and an $\alpha, \beta$-unsaturated imine moiety on the aryl scaffold. In the presence of $5 \mathrm{~mol} \%$ of $\mathbf{H 1 5}$, the functionalized substrates underwent the intramolecular [4+2] annulation in toluene at room temperature for $24 \mathrm{~h}$ to provide highly functionalized tetrahydropyridines in moderate to excellent yields with exceptionally high diastereo- and enantioselectivities. The optically pure products, containing multiple functional groups, could undergo further transformations, such as Diels-Alder reactions, reduction, and hydrolysis, to afford nitrogen-containing heterocyclic compounds. In contrast to the intermolecular aza-RC reaction/Michael addition sequence described above, the mechanism was assumed to involve an initial aza- $\mathrm{RC}$ reaction between the $\alpha, \beta$-unsaturated imine and the enolate, followed by an $\mathrm{S}_{\mathrm{N}} 2$ reaction.

\subsection{Annulations through double-Michael additions}

The bisphosphine-catalyzed double-Michael addition of dinucleophiles to electron-deficient alkynes provides an efficient approach for the synthesis of biologically significant nitrogen-containing heterocycles. To develop its asymmetric
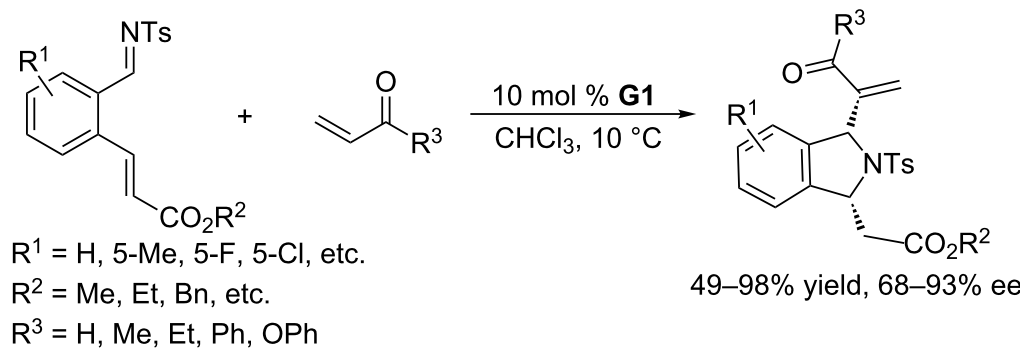

Scheme 50: Aza-MBH/Michael reactions, catalyzed by the chiral phosphine $\mathbf{G 1}$.

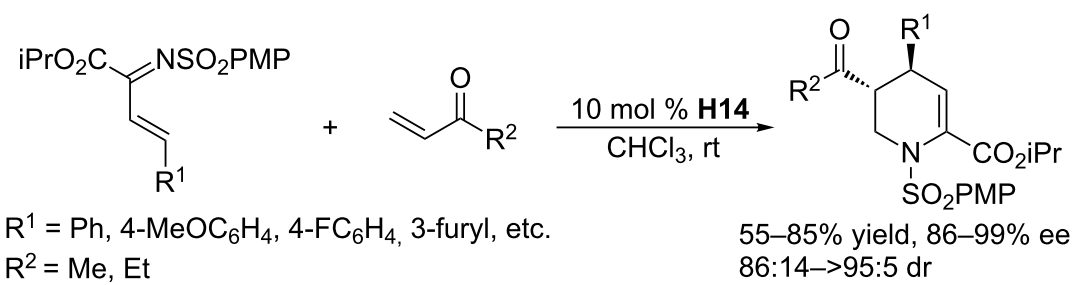

Scheme 51: Tandem RC/Michael additions, catalyzed by the chiral phosphine $\mathbf{H 1 4}$. 


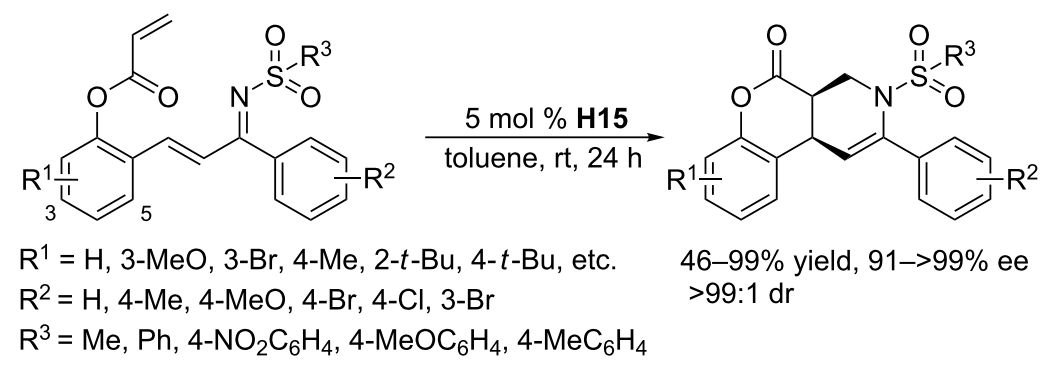

Scheme 52: Intramolecular tandem RC/Michael addition, catalyzed by the chiral phosphine $\mathbf{H 1 5}$

variant, Kwon and co-workers examined several common and commercially available chiral bisphosphines, as well as a series of newly prepared chiral aminophosphines [96]. Unfortunately, these phosphines displayed no or very poor enantioselectivity. In a relatively successful example, the chiral aminophosphine G9 catalyzed the asymmetric double-Michael reaction between $o$-tosylamidophenyl malonate and 3-butyn-2-one to give the indoline derivative in $69 \%$ yield and up to $10 \%$ ee (Scheme 53 ).

\subsection{Annulation through tandem Michael addition/ Wittig olefination}

In 2009, Tang and Zhou developed an annulation through tandem Michael addition/Wittig olefination, mediated by the chiral phosphine BIPHEP, for the synthesis of optically active cyclohexa-1,3-diene derivatives (Scheme 54) [97]. Although this reaction required a stoichiometric amount of chiral phosphine, it is quite interesting and deserves mention. In the presence of cesium carbonate, chiral BIPHEP-derived phosphonium ylides reacted with various $\alpha, \beta$-unsaturated aryl/alkylketones in THF at room temperature to afford corresponding cyclohexadienes in good yields and with up to $90 \%$ ee. It was proposed that the major enantiomer formed through $r e$-face attack of the ylide onto the Michael acceptor, rather than attack from the sterically hindered si-face.

\subsection{Michael additions}

Asymmetric Michael addition is one of the most studied enantioselective processes in organic synthesis, with many successful examples having been reported. Michael reactions employing nucleophilic phosphines are believed, however, to

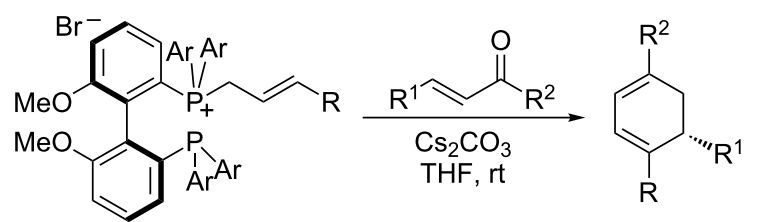

$\mathrm{Ar}=3-\mathrm{MeOC}_{6} \mathrm{H}_{4} ; \mathrm{R}=\mathrm{CO}_{2} \mathrm{Me}, \mathrm{CO}_{2} t-\mathrm{Bu}, \mathrm{Ph} \quad 53-79 \%$ yield $\mathrm{R}^{1}=\mathrm{Me}, \mathrm{Ph}, p-\mathrm{MeOC}_{6} \mathrm{H}_{4}, p-\mathrm{BrC}_{6} \mathrm{H}_{4}$, etc. $\quad 25-90 \%$ ee $\mathrm{R}^{2}=\mathrm{H}, \mathrm{Ph}$

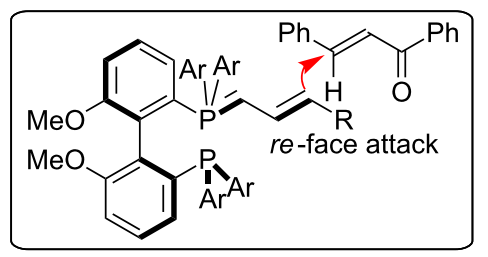

Scheme 54: Tandem Michael addition/Wittig olefinations, mediated by the chiral phosphine BIPHEP.

proceed through a mechanism involving phosphine-initiated general base catalysis; consequently, they do not involve covalent linkage of the phosphine to the reactants [98]. Accordingly, the development of chiral phosphine-assisted asymmetric Michael reactions has lagged behind other phosphine-catalyzed reactions. Recently, using bifunctional chiral amino acid-derived phosphines, Lu and co-workers developed asymmetric Michael additions of oxindoles to $\alpha, \beta$-unsaturated carbonyl compounds (Scheme 55) [99]. They identified the chiral phosphine $\mathbf{H 7}$ as the best catalyst, providing the corresponding Michael adducts in excellent yields and enantioselectivities. Notably, the less studied and relatively inert 3-alkyl-substituted<smiles>C#CC(=O)CC(C)COC(C)C</smiles><smiles>COC(=O)C1(C(=O)OC)c2ccccc2N([As])[C@H]1CC(C)=O</smiles>

$69 \%$ yield, $10 \%$ ee 


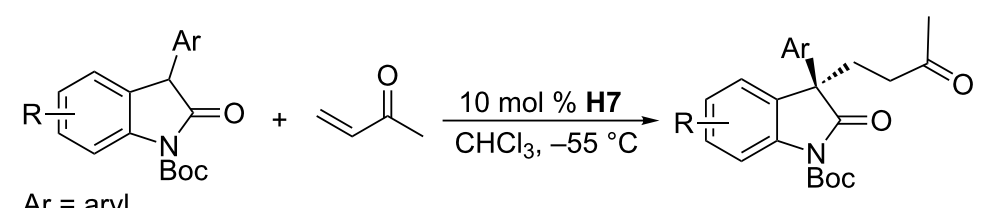

$\mathrm{Ar}=\operatorname{aryl}$

$\mathrm{R}=\mathrm{H}, 5-\mathrm{Me}, 5-\mathrm{F}, 7-\mathrm{F}, 7-\mathrm{Cl}, 5,7-\mathrm{Me}$

$89-97 \%$ yield, $86-96 \%$ ee

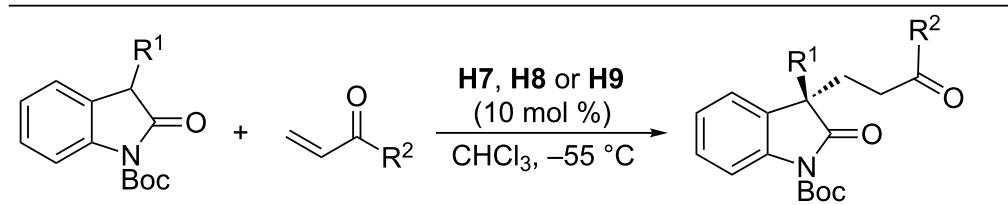

$\mathrm{R}^{1}=\mathrm{Bn}, 2$-naphthylmethyl, 2- $\mathrm{MeOC}_{6} \mathrm{H}_{4} \mathrm{CH}_{2}$, etc. $\quad 73-93 \%$ yield, $71-91 \%$ ee $\mathrm{R}^{2}=\mathrm{H}, \mathrm{Me}, \mathrm{Et}, \mathrm{Ph}$

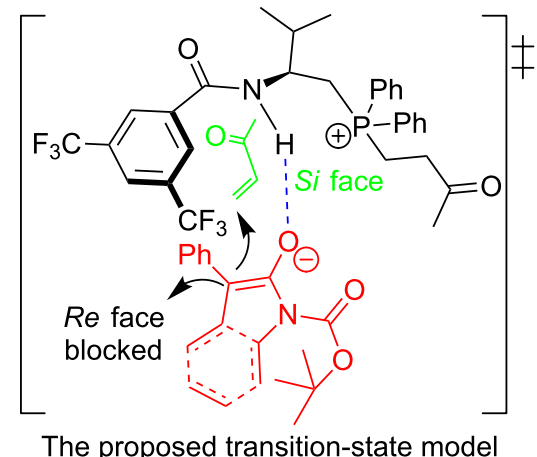

Scheme 55: Asymmetric Michael additions, catalyzed by the chiral phosphines $\mathbf{H 7}$, $\mathbf{H}$, and $\mathbf{H 9}$.

oxindoles were also applicable to the reaction in the presence various chiral phosphines. When exposed to appropriate catalysts (H7, H8, or H9), 3-alkyl-substituted oxindoles reacted smoothly with Michael acceptors for an extended period of time, giving an array of corresponding products in good to excellent yields and enantioselectivities. In the proposed transition state, a hydrogen bond between the amide NH proton and the enolate oxygen atom assisted the Michael addition from the $s i$-face of the enolate. The alternative re-face attack was blocked by the 3,5-bistrifluoromethylphenyl group (Scheme 55).

\section{$2.17 \mathrm{y}$-Umpolung additions of allenes or alkynes}

In the phosphine-catalyzed annulations of allenoates and activated alkenes, the first $\mathrm{C}-\mathrm{C}$ bond forms through nucleophilic addition of the $\beta$-phosphonium dienolate intermediate to the activated alkene at its $\alpha$ - or $\gamma$-carbon atoms. Conversely, when allenoates are mixed with pronucleophiles that contain acidic protons in the presence of a phosphine, the $\beta$-phosphonium dienolate zwitterion becomes protonated at its $\alpha$-carbon atom, resulting in the formation of vinylphosphonium species and anionic nucleophiles. The nucleophile anion then undergoes $\gamma$-umpolung addition to the $\gamma$-carbon atom of the vinylphosphonium species, producing a phosphonium ylide intermediate.
Subsequent proton transfer and $\beta$-elimination of the phosphine catalyst results in a $\gamma$-functionalized $\alpha, \beta$-unsaturated enoate. The reaction, known as $\gamma$-umpolung addition, was reported by Trost [100] and $\mathrm{Lu}$ [101] in 1994 and 1995, respectively. Trost employed butynoates, which are converted to $\beta$-phosphonium dienolates under the conditions of phosphine catalysis.

Early in 1998, the Zhang group explored phosphine-catalyzed asymmetric $\gamma$-umpolung addition of 2-butynoates and allenoates (Scheme 56) [102]. Using the cyclic chiral phosphine A1, featuring a bridged-ring skeleton, as the catalyst and $\mathrm{NaOAc} /$ HOAc as additives, asymmetric $\gamma$-addition of cyclic $\beta$-dicarbonyl nucleophiles to 2-butynoate occurred in toluene at relatively high temperature to produce $\gamma$-adducts with quaternary carbon centers in good to excellent yields (up to 93\%) and with moderate ee (up to $68 \%$ ). Under the same conditions, the allenoates also underwent the $\gamma$-addition to give corresponding products in up to $84 \%$ yield and with up to $81 \%$ ee. In 2004 , using the cyclic chiral phosphines E2 and E3, based on a five-membered phospholane ring skeleton, as catalysts, Pietrusiewicz and co-workers reinvestigated these reactions (Scheme 57) [103]. The catalytic activities and enantiocontrol provided by these chiral phosphanes were, however, unsatisfactory, leading to only low to moderate ee. 


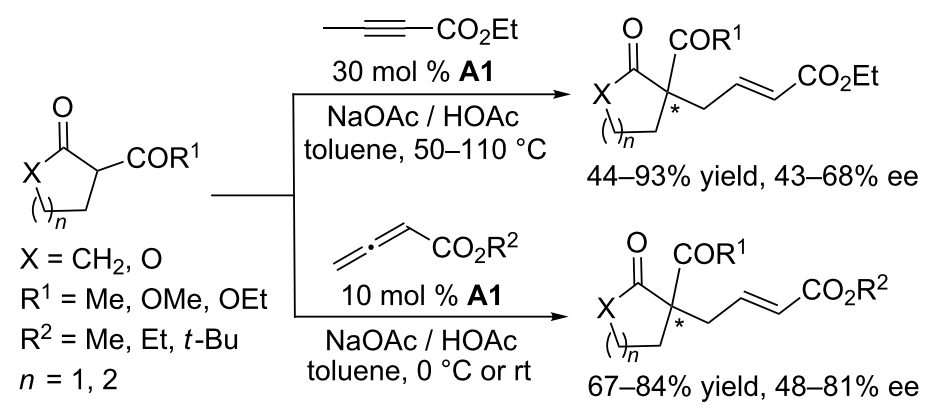

Scheme 56: Asymmetric $\gamma$-umpolung additions, catalyzed by the chiral phosphine $\mathbf{A} 1$.

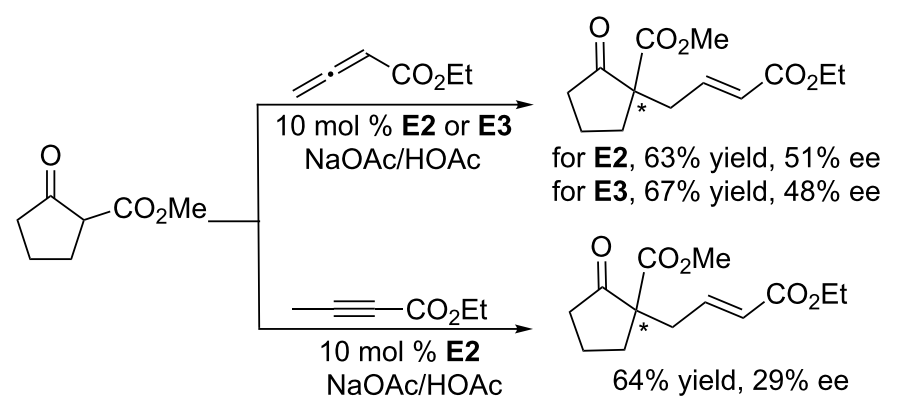

Scheme 57: Asymmetric $\mathrm{Y}$-umpolung additions, catalyzed by the chiral phosphines E2 and E3.

Although intermolecular $\gamma$-additions of 2-butynoates were quite unsuccessful, Fu and co-workers achieved successful $\gamma$-addition-based intramolecular annulations when using cyclic chiral phosphines featuring a spirocyclic skeleton (Scheme 58) [104]. In the presence of $10 \mathrm{~mol} \%$ of $\mathbf{D 2}$ and $50 \mathrm{~mol} \%$ of benzoic/4bromobenzoic acid as additives, $\gamma$-additions of a series of hydroxy-2-alkynoates occurred smoothly in THF at $50-55^{\circ} \mathrm{C}$ to give substituted tetrahydrofurans, tetrahydropyrans, and dihydrobenzopyrans in good to excellent yields (63-90\%) and enantioselectivities (87-94\% ee). Both alkanol and phenol derivatives were compatible with this catalytic system.

Building on the successful oxa-umpolung additions, $\mathrm{Fu}$ and co-workers further extended the reaction to intramolecular $\gamma$-additions of amino 2-alkynoates (Scheme 59) [105]. For this $\gamma$-addition of nitrogen nucleophiles, the chiral phosphine $\mathbf{D 2}$ remained the most effective catalyst. In the presence of $10 \mathrm{~mol} \%$ of D2 and 2,4-dimethoxyphenol as an additive,

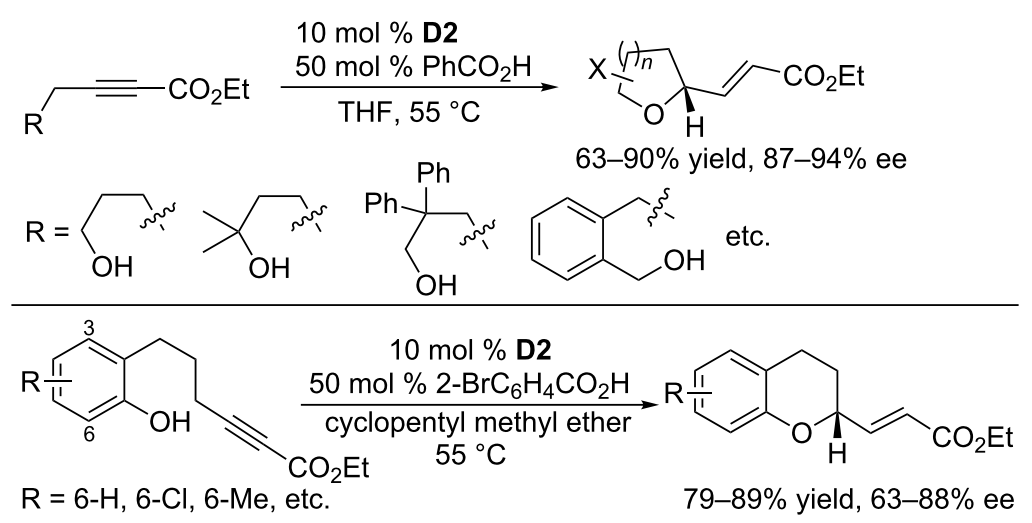

Scheme 58: Intramolecular Y-additions of hydroxy-2-alkynoates, catalyzed by the chiral phosphine D2. 


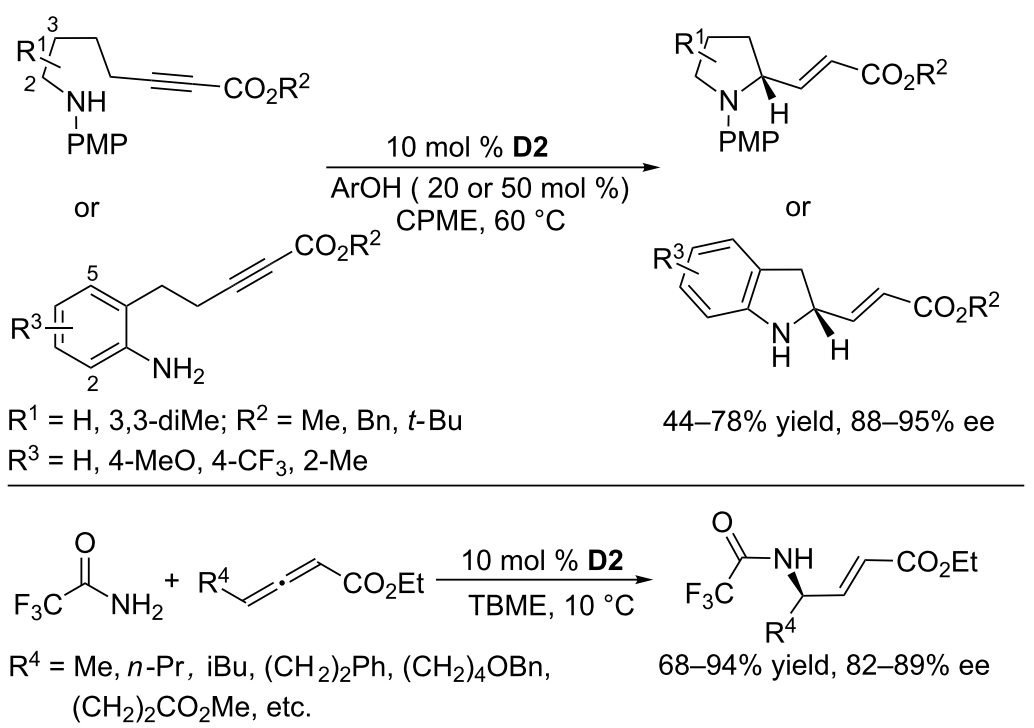

Scheme 59: Intra-/intermolecular $\mathrm{y}$-additions, catalyzed by the chiral phosphine D2.

intramolecular $\gamma$-additions of aromatic nitrogen nucleophiles to alkynoates occurred in cyclopentyl methyl ether at $60{ }^{\circ} \mathrm{C}$ to give functionalized pyrrolidines in moderate to good yields with excellent enantioselectivities (88-95\% ee). A wide range of substrates was well-tolerated. Gratifyingly, intermolecular $\gamma$-addition of a nitrogen nucleophile to allenes was also possible; in the presence of $10 \mathrm{~mol} \%$ of $\mathbf{D 2}$, the $\gamma$-addition reactions of 2,2,2-trifluoroacetamide to a variety of allenoates proceeded smoothly in tert-butyl methyl ether at $10{ }^{\circ} \mathrm{C}$, leading to a wide range of $\alpha, \beta$-unsaturated $\gamma$-amido carbonyl compounds in good to excellent yields and with high ee.

Using cyclic chiral phosphines based on a binaphthyl skeleton, $\mathrm{Fu}$ and co-workers also achieved $\gamma$-additions of nitromethane to allenoates [106]. In the presence of $10 \mathrm{~mol} \%$ of $\mathbf{B 5}$ and the assistance of $10 \mathrm{~mol} \%$ phenol, nitromethane underwent $\gamma$-additions to various allenoates in dioxane at room temperature (Scheme 60) to give corresponding $\alpha, \beta$-unsaturated $\delta$-nitro carbonyl compounds with good catalytic efficiency (57-94\% yields, $81-97 \%$ ee). In the further exploration, using $10 \mathrm{~mol} \%$ of the chiral phosphine $\mathbf{B 3}$ as the catalyst and $10 \mathrm{~mol} \%$ of 2-methoxyphenol as an additive, the $\gamma$-additions of malonate esters to allenoates were also successfully developed [107]. The $\gamma$-additions between a wide array of racemic allenoates and malonate esters proceeded well in toluene at $-30{ }^{\circ} \mathrm{C}$, furnishing a variety of the corresponding $\gamma$-substituted $\alpha, \beta$-unsaturated esters in good yields with good to excellent enantioselectivities (Scheme 60). Notably, the $\alpha$-substituted malonate esters could

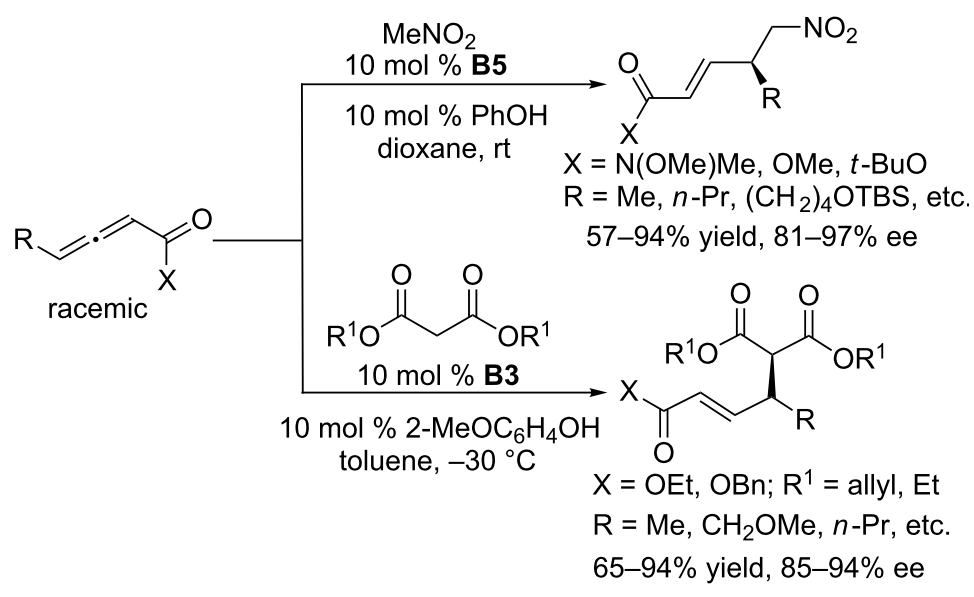

Scheme 60: Intermolecular $\gamma$-additions, catalyzed by the chiral phosphines B5 and B3. 
react with the allenoates to provide optically active $\alpha, \beta$-unsaturated carbonyl compounds featuring two adjacent carbon stereocenters: a chiral quaternary carbon atom and a chiral tertiary carbon atom.

In subsequent investigations, Fu and co-workers further demonstrated that alkyl and aryl thiols could also act as nucleophiles for asymmetric $\gamma$-additions to various allenoates [108,109]. In the presence of $10 \mathrm{~mol} \%$ of TangPhos E6 as the catalyst and $50 \mathrm{~mol} \%$ of 2-methyl-2-phenylpropionic acid as an additive, alkyl thiols underwent $\gamma$-additions to various allenoates in toluene at room temperature to give $\gamma$-thioesters in $67-89 \%$ yields and with $85-95 \%$ ee (Scheme 61) [108]. Notably, the enantioselectivities were significantly additive-dependent. For the asymmetric $\gamma$-additions of aryl thiols to allenoates, the chiral binaphthyl phosphine $\mathbf{B} 4$ proved to be the best catalyst [109]. In the presence of $10 \mathrm{~mol} \%$ of $\mathbf{B} 4$ as the catalyst and pivalic acid as an additive, the $\gamma$-additions between various aryl thiols and an array of allenoates progressed well in toluene at $10{ }^{\circ} \mathrm{C}$ to afford $\gamma$-arylthio- $\alpha, \beta$-unsaturated esters in $58-81 \%$ yields and with $81-95 \%$ ee. This reaction provides facile access to various chiral alkyl aryl thioethers under mild conditions.

\subsection{Allylic substitutions of $\mathrm{MBH}$ acetates or carbon- ates with nucleophiles}

In addition to various annulations, allylic substitution is another important class of reaction of $\mathrm{MBH}$ acetates or carbonates in nucleophilic phosphine catalysis that can be used to synthesize valuable molecules.

For the synthesis of $\gamma$-butenolide ring systems, which are very common structural motifs in naturally occurring organic molecules, the Krische group developed $\mathrm{PPh}_{3}$-catalyzed allylic substitutions of MBH acetates with 2-(trimethylsilyloxy)furan [110,111]. Using the bifunctional chiral phosphine G2, Shi and co-workers accomplished the asymmetric variant of this reaction (Scheme 62) [112]. In the presence of $10 \mathrm{~mol} \%$ of $\mathbf{G 2}$ and excess water (6 equiv), which was assumed to function as an

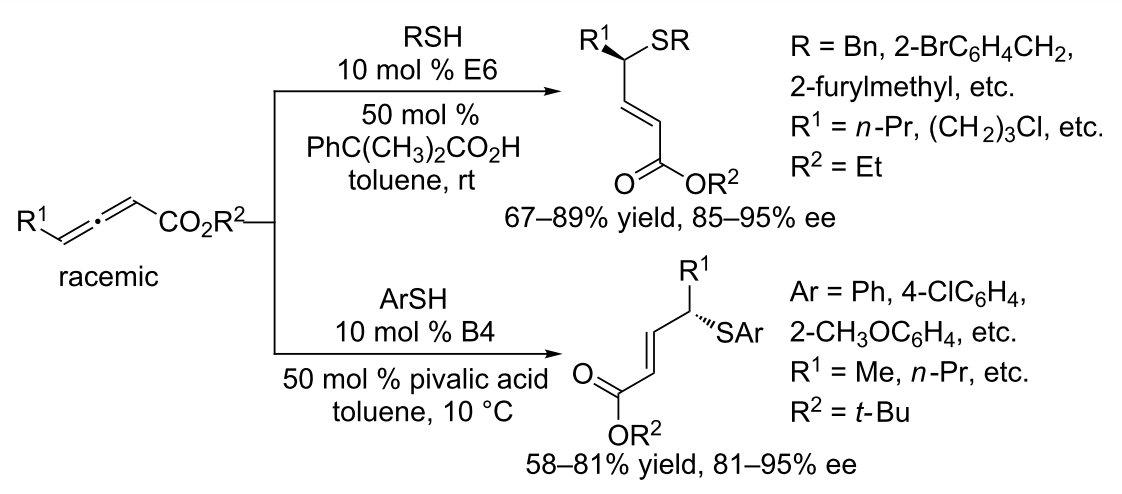

Scheme 61: Intermolecular $\gamma$-additions, catalyzed by the chiral phosphines E6 and B4.
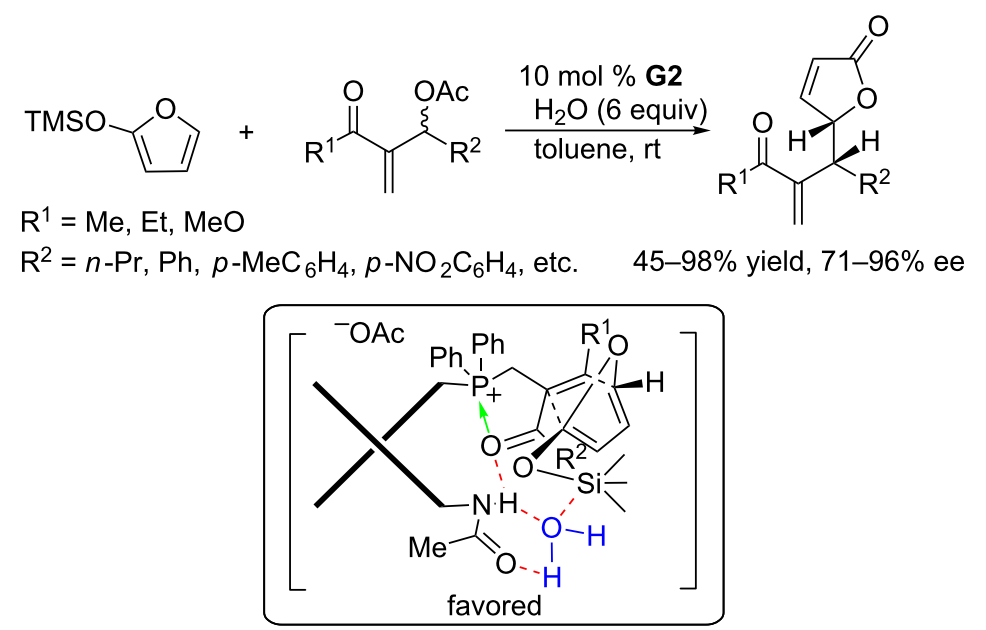

Scheme 62: Asymmetric allylic substitution of MBH acetates, catalyzed by the chiral phosphine $\mathbf{G 2}$. 
extra proton source, the allylic substitutions of $\mathrm{MBH}$ acetates bearing either aromatic or aliphatic substituents at the allylic position with 2-(trimethylsilyloxy)furan proceeded smoothly in toluene to afford enantioenriched $\gamma$-butenolides in moderate to excellent yields and with excellent enantioselectivities. An intermediate arising from endo-selective Diels-Alder annulation of the siloxy-furan complex with the enone was believed to play a key role in the enantiocontrol (Scheme 62). In the intermediate, a molecule of water served as a bridge of hydrogen bonds to connect the amide $\mathrm{NH}$ proton of the phosphonium ylide to the silicon atom of the trimethylsilyloxy group, which directed the approaching furan moiety to the Michael acceptor in an endo manner.

Using multifunctional chiral phosphines based on a binaphthyl skeleton, Shi and co-workers explored the phosphine-catalyzed asymmetric allylic substitutions of MBH acetates or carbonates with various nucleophiles, both experimentally and theoretically. In the presence of chiral phosphines presenting tethered amide or thiourea moieties $(\mathbf{G 2}, \mathbf{G 3}, \mathbf{G 4}, \mathbf{G 8})$, various activated nucleophiles, including phthalimide [113,114], oxazolones [115], and benzofuran-2(3H)-ones and oxindoles [116], could undergo substitution reactions with $\mathrm{MBH}$ acetates or carbonates, generating a variety of optically active $\mathrm{MBH}$ adducts in good yields and stereoselectivities (Scheme 63). Theoretical calculations were performed to explore the origins of stereoselectivities and to confirm Shi's previously proposed mechanism [117]. The MP2/6-31G(d)//HF/3-21G* level of theory was used to calculate and compare the energies of the transition states. The calculations revealed that the energy of the transition state for endo-Diels-Alder [4 + 2] annulation was the lowest among the four possible transition states, presumably arising from the $\pi-\pi$-stacking interactions; these energy gaps likely account for the diastereoselection. Furthermore, the enantioselectivity was ascribed to the energy difference between the transition states for the two possible faces of attack (re- and si-endo transition states), on the basis of optimized structures. The $s i$-endo transition state was disfavored because of additional repulsion between the trimethylsilyloxy unit and the phosphine, as well as the absence of hydrogen bonding between the amide $\mathrm{NH}$ proton and the $\mathrm{C}=\mathrm{O}$ group in the $\mathrm{MBH}$ adduct.

\subsection{Asymmetric acylations of alcohols}

Kinetic resolution of a racemic mixture is a powerful tool for the synthesis of enantioenriched compounds. Among the various methods, including enzyme catalysis, metal catalysis, and organocatalysis, that have been developed for this process, phosphine catalysis is particularly interesting. In 1996, Vedejs and co-workers reported the first example of chiral phosphinecatalyzed enantioselective acylation based on kinetic resolution<smiles>[R]C(=O)C(=C)C1([R])C(=O)N2c3ccc([R])cc3C1([R])C2[R]</smiles><smiles>[R]C(=O)C(=C)C([R])C1([R])C(=O)Oc2ccc([R3])cc21</smiles>
84->99\% yield, $90-97 \%$ ee (syn) 54:46-71:29 dr (syn:anti) $76-93 \%$ yield, $91-98 \%$ ee (anti) 51:49-67:33 dr (anti:syn)

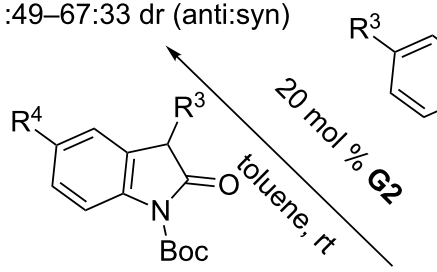<smiles>[R]C(=O)C(=C)C([R])([R])[C@H]1C=CC(=O)O1</smiles>
$>95: 5 \mathrm{dr}$<smiles>[R]C(=C)C(=C)C([R])[Y1]([H])([H])N1C(=O)c2ccccc2C1=O</smiles><smiles>[R]C(=O)C(=C)C([R])O[R6](=O)OCc1ccccc1</smiles><smiles>[R]C1N=C(Pc2ccccc2)OC1=O</smiles>

OTMS

$\mathrm{R}^{1}=$ alkyl, $\mathrm{Ar}$ $\mathrm{R}^{2}=$ alkyl, alkoxy

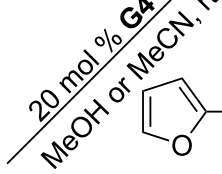<smiles>[R2]C(=O)C(=C)C([R1])C1([R])N=C(c2ccccc2)OC1=O</smiles>

$85-99 \%$ ee

$3: 1-20: 1 d r$

70-91\% yield, $34-78 \%$ ee 
(Scheme 64) [19]. They demonstrated that the cyclic chiral phosphines $\mathbf{E} 4$ and $\mathbf{E 5}$ catalyze the acetylation and benzoylation of secondary alcohols effectively in dichloromethane, yielding corresponding esters in moderate to good conversions and with moderate enantioselectivities. For instance, in the presence of 5-8 $\mathrm{mol} \%$ of $\mathbf{E 4}$, the desymmetrization reaction of cis1,2-cyclohexanediol with acetic anhydride in dichloromethane at $0-20{ }^{\circ} \mathrm{C}$ gave the monoacetate in $66 \%$ conversion and with $62-67 \%$ ee. Using $16 \mathrm{~mol} \%$ of $\mathbf{E 5}$, the reaction of mesohydrobenzoin with benzoic anhydride afforded the monobenzoate in $70 \%$ conversion and with $58 \%$ ee.

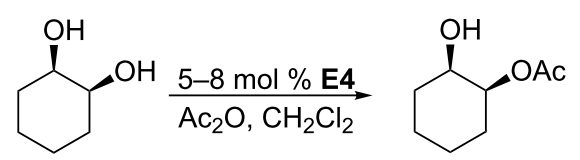

$66 \%$ conv, $62-67 \%$ ee

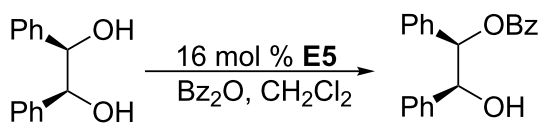

$70 \%$ conv, $58 \%$ ee

Scheme 64: Asymmetric acylation of diols, catalyzed by the chiral phosphines E4 and E5.

In a subsequent study, Vedejs and co-workers developed more efficient and enantioselective chiral phosphines - E8 and E9 for the kinetic resolution (Scheme 65) [20]. In the presence of 2-12 mol \% of E8 or E9, racemic secondary alcohols reacted with $(\mathrm{iPrCO})_{2} \mathrm{O}$ in heptane to provide isobutyrates in moderate conversions and with good to excellent enantioselectivities. At the same time, the starting materials were kinetically resolved into corresponding enantioenriched alcohols. Moreover, this kinetic resolution could be performed on the gram-scale.

\section{Conclusion}

This review reveals that, in less than two decades, tremendous progress has been made in the study of asymmetric reactions catalyzed by nucleophilic chiral phosphines. These reactions have emerged as attractive and powerful synthetic tools, allowing the convenient preparation of many enantioenriched and functionalized carbocycles, heterocycles, and acyclic com- pounds in satisfactory yields. Nevertheless, the range of successful asymmetric reaction types remains relatively limited. Although many chiral phosphines have been prepared, the number of appropriate and available chiral phosphines is small when compared with those that mediate achiral reactions. Because of the lack of suitable chiral catalysts, asymmetric variants of many phosphine-catalyzed reactions remain unsubstantiated. Even for those successful asymmetric reactions, quite a few catalyst systems are substrate-dependent and do not work for slightly different, yet analogous, substrates. Based on these issues, the design and synthesis of novel chiral phosphines, including cyclic phosphines and multifunctional chiral phosphines, remains an interesting challenge. Because of the powerful capabilities of phosphine-catalyzed reactions in the synthesis of biologically active molecules and natural products, there is a need for further research in this area, such that more asymmetric reactions can be anticipated.

\section{Acknowledgements}

We thank the NIH (GM071779, to O.K.) and the National Natural Science Foundation of China for research support (Nos. 21172253 and 21372256 , to H.G.).

\section{References}

1. Lu, X.; Zhang, C.; Xu, Z. Acc. Chem. Res. 2001, 34, 535-544. doi:10.1021/ar000253x

2. Valentine, D. H., Jr.; Hillhouse, J. H. Synthesis 2003, 317-334. doi:10.1055/s-2003-37337

3. Methot, J. L.; Roush, W. R. Adv. Synth. Catal. 2004, 346, 1035-1050. doi:10.1002/adsc.200404087

4. Lu, X.; Du, Y.; Lu, C. Pure Appl. Chem. 2005, 77, 1985-1990. doi:10.1351/pac200577121985

5. Nair, V.; Menon, R. S.; Sreekanth, A. R.; Abhilash, N.; Biju, A. T. Acc. Chem. Res. 2006, 39, 520-530. doi:10.1021/ar0502026

6. Ye, L.-W.; Zhou, J.; Tang, Y. Chem. Soc. Rev. 2008, 37, 1140-1152. doi:10.1039/b717758e

7. Denmark, S. E.; Beutner, G. L. Angew. Chem., Int. Ed. 2008, 47, 1560-1638. doi:10.1002/anie.200604943

8. Kwong, C. K.-W.; Fu, M. Y.; Lam, C. S.-L.; Toy, P. H. Synthesis 2008, 2307-2317. doi:10.1055/s-2008-1067173

9. Aroyan, C. E.; Dermenci, A.; Miller, S. J. Tetrahedron 2009, 65, 4069-4084. doi:10.1016/j.tet.2009.02.066

10. Cowen, B. J.; Miller, S. J. Chem. Soc. Rev. 2009, 38, 3102-3116. doi:10.1039/b816700c

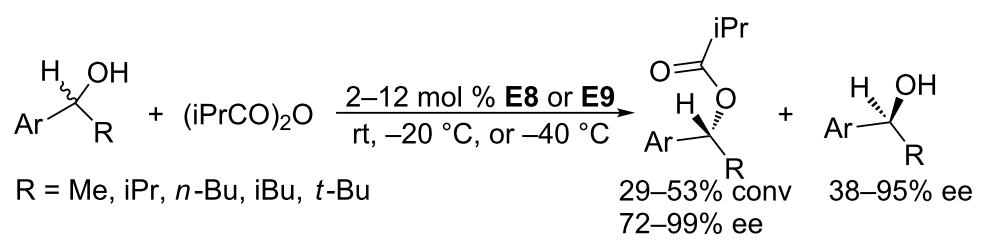

Scheme 65: Kinetic resolution of secondary alcohols, catalyzed by the chiral phosphine E8 and E9. 
11. Marinetti, A.; Voituriez, A. Synlett 2010, 174-194. doi:10.1055/s-0029-1219157

12. Kolesinska, B. Cent. Eur. J. Chem. 2010, 8, 1147-1171. doi:10.2478/s11532-010-0114-Z

13. Wang, S.-X.; Han, X.; Zhong, F.; Wang, Y.; Lu, Y. Synlett 2011, 2766-2778. doi:10.1055/s-0031-1289538

14. Zhao, Q.-Y.; Lian, Z.; Wei, Y.; Shi, M. Chem. Commun. 2012, 48, 1724-1732. doi:10.1039/c1cc15793k

15. Yu, S.; Ma, S. Angew. Chem., Int. Ed. 2012, 51, 3074-3112. doi:10.1002/anie.201101460

16. Wang, Y.; Pan, J.; Chen, Z.; Sun, X.; Wang, Z. Mini-Rev. Med. Chem. 2013, 13, 836-844. doi:10.2174/1389557511313060006

17. Fan, Y. C.; Kwon, O. Chem. Commun. 2013, 49, 11588-11619. doi:10.1039/c3cc47368f

18. Wang, Z.; Xu, X.; Kwon, O. Chem. Soc. Rev. 2014, 43, 2927-2940. doi:10.1039/c4cs00054d

19. Vedejs, E.; Daugulis, O.; Diver, S. T. J. Org. Chem. 1996, 61, 430-431. doi:10.1021/jo951661v

20. Vedejs, E.; Daugulis, O. J. Am. Chem. Soc. 1999, 121, 5813-5814. doi:10.1021/ja990133o

21. Shi, M.; Chen, L.-H. Pure Appl. Chem. 2005, 77, 2105-2110. doi:10.1351/pac200577122105

22. Masson, G.; Housseman, C.; Zhu, J. Angew. Chem., Int. Ed. 2007, 46, 4614-4628. doi:10.1002/anie.200604366

23. Declerck, V.; Martinez, J.; Lamaty, F. Chem. Rev. 2009, 109, 1-48. doi:10.1021/cr068057c

24. Ma, G.-N.; Jiang, J.-J.; Shi, M.; Wei, Y. Chem. Commun. 2009, 5496-5514. doi:10.1039/b909405a

25. Wei, Y.; Shi, M. Acc. Chem. Res. 2010, 43, 1005-1018. doi:10.1021/ar900271g

26. Wei, Y.; Shi, M. Chem. Rev. 2013, 113, 6659-6690. doi:10.1021/cr300192h

27. Tang, W.; Zhang, X. Chem. Rev. 2003, 103, 3029-3070. doi:10.1021/cr020049i

28. Pereira, M. M.; Calvete, M. J. F.; Carrilho, R. M. B.; Abreu, A. R. Chem. Soc. Rev. 2013, 42, 6990-7027. doi:10.1039/c3cs60116a

29. Zhang, W.; Chi, Y.; Zhang, X. Acc. Chem. Res. 2007, 40, 1278-1290. doi:10.1021/ar7000028

30. Kamer, P. C. J.; van Leeuwen, P. W. N. M. Phosphorus (III) Ligands in Homogeneous Catalysis: Design and Synthesis; John Wiley \& Sons: Chichester, UK, 2012. doi:10.1002/9781118299715

31. Doyle, A. G.; Jacobsen, E. N. Chem. Rev. 2007, 107, 5713-5743. doi:10.1021/cr068373r

32. Davie, E. A. C.; Mennen, S. M.; Xu, Y.; Miller, S. J. Chem. Rev. 2007, 107, 5759-5812. doi:10.1021/cr068377w

33. Zhu, G.; Chen, Z.; Jiang, Q.; Xiao, D.; Cao, P.; Zhang, X. J. Am. Chem. Soc. 1997, 119, 3836-3837. doi:10.1021/ja9644687

34. Zhang, C.; Lu, X. J. Org. Chem. 1995, 60, 2906-2908. doi:10.1021/jo00114a048

35. Wilson, J. E.; Fu, G. C. Angew. Chem., Int. Ed. 2006, 45, 1426-1429. doi:10.1002/anie.200503312

36. Fujiwara, Y.; Fu, G. C. J. Am. Chem. Soc. 2011, 133, 12293-12297. doi:10.1021/ja2049012

37. Schuler, M.; Voituriez, A.; Marinetti, A. Tetrahedron: Asymmetry 2010, 21, 1569-1573. doi:10.1016/j.tetasy.2010.04.014

38. Voituriez, A.; Pinto, N.; Neel, M.; Retailleau, P.; Marinetti, A. Chem. - Eur. J. 2010, 16, 12541-12544. doi:10.1002/chem.201001791

39. Pinto, N.; Retailleau, P.; Voituriez, A.; Marinetti, A. Chem. Commun. 2011, 47, 1015-1017. doi:10.1039/c0cc03164j
40. Steurer, M.; Jensen, K. L.; Worgull, D.; Jørgensen, K. A. Chem. - Eur. J. 2012, 18, 76-79. doi:10.1002/chem.201103502

41. Marco-Martinez, J.; Marcos, V.; Reboredo, S.; Filippone, S.; Martin, N. Angew. Chem., Int. Ed. 2013, 52, 5115-5119. doi:10.1002/anie.201301292

42. O'Donovan, B. F.; Hitchcock, P. B.; Meidine, M. F.; Kroto, H. W.; Taylor, R.; Walton, D. R. M. Chem. Commun. 1997, 81-82. doi:10.1039/a606458b

43. Guo, L.-W.; Gao, X.; Zhang, D.-W.; Wu, S.-H.; Wu, H.-M. Chin. J. Chem. 2002, 20, 1430-1433. doi:10.1002/cjoc.20020201146

44. Voituriez, A.; Panossian, A.; Fleury-Brégeot, N.; Retailleau, P.; Marinetti, A. J. Am. Chem. Soc. 2008, 130, 14030-14031. doi:10.1021/ja806060a

45. Voituriez, A.; Panossian, A.; Fleury-Brégeot, N.; Retailleau, P.; Marinetti, A. Adv. Synth. Catal. 2009, 351, 1968-1976. doi:10.1002/adsc.200900193

46. Pinto, N.; Neel, M.; Panossian, A.; Retailleau, P.; Frison, G.; Voituriez, A.; Marinetti, A. Chem. - Eur. J. 2010, 16, 1033-1045. doi:10.1002/chem.200901893

47. Neel, M.; Gouin, J.; Voituriez, A.; Marinetti, A. Synthesis 2011, 2003-2009. doi:10.1055/s-0030-1260466

48. Duvvuru, D.; Pinto, N.; Gomez, C.; Betzer, J.-F.; Retailleau, P.; Voituriez, A.; Marinetti, A. Adv. Synth. Catal. 2012, 354, 408-414. doi:10.1002/adsc.201100748

49. Wang, D.; Wei, Y.; Shi, M. Chem. Commun. 2012, 48, 2764-2766. doi:10.1039/c2cc17709a

50. Sampath, M.; Loh, T.-P. Chem. Commun. 2009, 1568-1570. doi:10.1039/b819959k

51. Wallace, D. J.; Sidda, R. L.; Reamer, R. A. J. Org. Chem. 2007, 72, 1051-1054. doi:10.1021/jo062170l

52. Cowen, B. J.; Miller, S. J. J. Am. Chem. Soc. 2007, 129, 10988-10989. doi:10.1021/ja0734243

53. Xiao, H.; Chai, Z.; Zheng, C.-W.; Yang, Y.-Q.; Liu, W.; Zhang, J.-K.; Zhao, G. Angew. Chem., Int. Ed. 2010, 49, 4467-4470. doi:10.1002/anie.201000446

54. Han, X.; Wang, Y.; Zhong, F.; Lu, Y. J. Am. Chem. Soc. 2011, 133, 1726-1729. doi:10.1021/ja1106282

55. Han, X.; Wang, S.-X.; Zhong, F.; Lu, Y. Synthesis 2011, 1859-1864. doi:10.1055/s-0030-1260460

56. Zhao, Q.; Han, X.; Wei, Y.; Shi, M.; Lu, Y. Chem. Commun. 2012, 48, 970-972. doi:10.1039/c2cc16904e

57. Zhang, X.-N.; Shi, M. ACS Catal. 2013, 3, 507-512. doi:10.1021/cs300751a

58. Xu, Z.; Lu, X. Tetrahedron Lett. 1997, 38, 3461-3464. doi:10.1016/S0040-4039(97)00656-4

59. Xu, Z.; Lu, X. J. Org. Chem. 1998, 63, 5031-5041. doi:10.1021/jo9723063

60. Xu, Z.; Lu, X. Tetrahedron Lett. 1999, 40, 549-552. doi:10.1016/S0040-4039(98)02405-8

61. Jean, L.; Marinetti, A. Tetrahedron Lett. 2006, 47, 2141-2145. doi:10.1016/j.tetlet.2006.01.122

62. Scherer, A.; Gladysz, J. A. Tetrahedron Lett. 2006, 47, 6335-6337. doi:10.1016/j.tetlet.2006.07.005

63. Fleury-Brégeot, N.; Jean, L.; Retailleau, P.; Marinetti, A. Tetrahedron 2007, 63, 11920-11927. doi:10.1016/j.tet.2007.09.022

64. Pinto, N.; Fleury-Brégeot, N.; Marinetti, A. Eur. J. Org. Chem. 2009, 146-151. doi:10.1002/ejoc.200800598

65. Panossian, A.; Fleury-Brégeot, N.; Marinetti, A. Eur. J. Org. Chem. 2008, 3826-3833. doi:10.1002/ejoc.200800347 
66. Andrews, I. P.; Kwon, O. Chem. Sci. 2012, 3, 2510-2514. doi:10.1039/c2sc20468a

67. Fang, Y.-Q.; Jacobsen, E. N. J. Am. Chem. Soc. 2008, 130, 5660-5661. doi:10.1021/ja801344w

68. Han, X.; Zhong, F.; Wang, Y.; Lu, Y. Angew. Chem., Int. Ed. 2012, 51, 767-770. doi:10.1002/anie.201106672

69. Na, R.; Jing, C.; Xu, Q.; Jiang, H.; Wu, X.; Shi, J.; Zhong, J.; Wang, M.; Benitez, D.; Tkatchouk, E.; Goddard, W. A., III; Guo, H.; Kwon, O. J. Am. Chem. Soc. 2011, 133, 13337-13348. doi:10.1021/ja200231v

70. Sampath, M.; Loh, T.-P. Chem. Sci. 2010, 1, 739-742. doi:10.1039/c0sc00123f

71. Liu, T.-Y.; Xie, M.; Chen, Y.-C. Chem. Soc. Rev. 2012, 41, 4101-4112. doi:10.1039/c2cs35017c

72. Rios, R. Catal. Sci. Technol. 2012, 2, 267-278. doi:10.1039/c1cy00387a

73. Wang, Q.-G.; Zhu, S.-F.; Ye, L.-W.; Zhou, C.-Y.; Sun, X.-L.; Tang, Y.; Zhou, Q.-L. Adv. Synth. Catal. 2010, 352, 1914-1919. doi:10.1002/adsc.201000129

74. Tan, B.; Candeias, N. R.; Barbas, C. F., III. J. Am. Chem. Soc. 2011, 133, 4672-4675. doi:10.1021/ja110147w

75. Albertshofer, K.; Tan, B.; Barbas, C. F., III. Org. Lett. 2013, 15, 2958-2961. doi:10.1021/ol401087a

76. Zhong, F.; Han, X.; Wang, Y.; Lu, Y. Angew. Chem., Int. Ed. 2011, 50, 7837-7841. doi:10.1002/anie.201102094

77. Deng, H.-P.; Wei, Y.; Shi, M. Org. Lett. 2011, 13, 3348-3351. doi:10.1021/ol201094f

78. Zhong, F.; Chen, G.-Y.; Han, X.; Yao, W.; Lu, Y. Org. Lett. 2012, 14, 3764-3767. doi:10.1021/ol301647g

79. Deng, H.-P.; Wang, D.; Wei, Y.; Shi, M. Beilstein J. Org. Chem. 2012, 8, 1098-1104. doi:10.3762/bjoc.8.121

80. Deng, H.-P.; Wei, Y.; Shi, M. Adv. Synth. Catal. 2012, 354, 783-789. doi:10.1002/adsc.201101012

81. Hu, F.; Wei, Y.; Shi, M. Tetrahedron 2012, 68, 7911-7919. doi:10.1016/j.tet.2012.07.013

82. Lian, Z.; Shi, M. Org. Biomol. Chem. 2012, 10, 8048-8050. doi:10.1039/c2ob25801c

83. Zhu, X.-F.; Lan, J.; Kwon, O. J. Am. Chem. Soc. 2003, 125, 4716-4717. doi:10.1021/ja0344009

84. Wurz, R. P.; Fu, G. C. J. Am. Chem. Soc. 2005, 127, 12234-12235. doi:10.1021/ja053277d

85. Xiao, H.; Chai, Z.; Wang, H.-F.; Wang, X.-W.; Cao, D.-D.; Liu, W.; Lu, Y.-P.; Yang, Y.-Q.; Zhao, G. Chem. - Eur. J. 2011, 17, 10562-10565. doi:10.1002/chem.201100850

86. Tran, Y. S.; Kwon, O. J. Am. Chem. Soc. 2007, 129, 12632-12633. doi:10.1021/ja0752181

87. Tran, Y. S.; Martin, T. J.; Kwon, O. Chem. - Asian J. 2011, 6, 2101-2106. doi:10.1002/asia.201100190

88. Zhong, F.; Han, X.; Wang, Y.; Lu, Y. Chem. Sci. 2012, 3, 1231-1234. doi:10.1039/c2sc00963c

89. Xiao, H.; Chai, Z.; Cao, D.; Wang, H.; Chen, J.; Zhao, G. Org. Biomol. Chem. 2012, 10, 3195-3201. doi:10.1039/c2ob25295c

90. Chen, S.; Salo, E. C.; Wheeler, K. A.; Kerrigan, N. J. Org. Lett. 2012, 14, 1784-1787. doi:10.1021/ol3003783

91. Zhang, X.-n.; Deng, H.-P.; Huang, L.; Wei, Y.; Shi, M. Chem. Commun. 2012, 48, 8664-8666. doi:10.1039/c2cc34619b

92. Ibrahim, A. A.; Wei, P.-H.; Harzmann, G. D.; Kerrigan, N. J. J. Org. Chem. 2010, 75, 7901-7904. doi:10.1021/jo101867m

93. Takizawa, S.; Inoue, N.; Hirata, S.; Sasai, H. Angew. Chem., Int. Ed. 2010, 49, 9725-9729. doi:10.1002/anie.201004547
94. Shi, Z.; Yu, P.; Loh, T.-P.; Zhong, G. Angew. Chem., Int. Ed. 2012, 51, 7825-7829. doi:10.1002/anie.201203316

95. Jin, Z.; Yang, R.; Du, Y.; Tiwari, B.; Ganguly, R.; Chi, Y. R. Org. Lett. 2012, 14, 3226-3229. doi:10.1021/ol3013588

96. Khong, S. N.; Kwon, O. Molecules 2012, 17, 5626-5650. doi:10.3390/molecules17055626

97. Ye, L.-W.; Wang, S.-B.; Wang, Q.-G.; Sun, X.-L.; Tang, Y.; Zhou, Y.-G. Chem. Commun. 2009, 3092-3094. doi:10.1039/b900048h

98. White, D. A.; Baizer, M. M. Tetrahedron Lett. 1973, 14, 3597-3600. doi:10.1016/S0040-4039(01)86980-X

99. Zhong, F.; Dou, X.; Han, X.; Yao, W.; Zhu, Q.; Meng, Y.; Lu, Y. Angew. Chem., Int. Ed. 2013, 52, 943-947. doi:10.1002/anie.201208285

100. Trost, B. M.; Li, C.-J. J. Am. Chem. Soc. 1994, 116, 3167-3168. doi:10.1021/ja00086a074

101.Zhang, C.; Lu, X. Synlett 1995, 645-646. doi:10.1055/s-1995-5042 102.Chen, Z.; Zhu, G.; Jiang, Q.; Xiao, D.; Cao, P.; Zhang, X. J. Org. Chem. 1998, 63, 5631-5635. doi:10.1021/jo9721756

103.Pakulski, Z.; Demchuk, O. M.; Frelek, J.; Luboradzki, R.; Pietrusiewicz, K. M. Eur. J. Org. Chem. 2004, 3913-3918. doi:10.1002/ejoc.200400186

104.Chung, Y. K.; Fu, G. C. Angew. Chem., Int. Ed. 2009, 48, 2225-2227. doi:10.1002/anie.200805377

105.Lundgren, R. J.; Wilsily, A.; Marion, N.; Ma, C.; Chung, Y. K.; Fu, G. C. Angew. Chem., Int. Ed. 2013, 52, 2525-2528. doi:10.1002/anie.201208957

106. Smith, S. W.; Fu, G. C. J. Am. Chem. Soc. 2009, 131, 14231-14233. doi:10.1021/ja9061823

107.Sinisi, R.; Sun, J.; Fu, G. C. Proc. Natl. Acad. Sci. U. S. A. 2010, 107, 20652-20654. doi:10.1073/pnas.1003597107

108.Sun, J.; Fu, G. C. J. Am. Chem. Soc. 2010, 132, 4568-4569. doi:10.1021/ja101251d

109.Fujiwara, Y.; Sun, J.; Fu, G. C. Chem. Sci. 2011, 2, 2196-2198. doi:10.1039/c1sc00414j

110.Cho, C.-W.; Kong, J.-R.; Krische, M. J. Org. Lett. 2004, 6, 1337-1339. doi:10.1021/ol049600j

111. Cho, C.-W.; Krische, M. J. Angew. Chem., Int. Ed. 2004, 43, 6689-6691. doi:10.1002/anie.200461381

112.Jiang, Y.-Q.; Shi, Y.-L.; Shi, M. J. Am. Chem. Soc. 2008, 130 7202-7203. doi:10.1021/ja802422d

113.Ma, G.-N.; Cao, S.-H.; Shi, M. Tetrahedron: Asymmetry 2009, 20, 1086-1092. doi:10.1016/j.tetasy.2009.03.040

114.Deng, H.-P.; Wei, Y.; Shi, M. Eur. J. Org. Chem. 2011, 1956-1960. doi:10.1002/ejoc.201001660

115. Yang, Y.-L.; Pei, C.-K.; Shi, M. Org. Biomol. Chem. 2011, 9, 3349-3358. doi:10.1039/c1ob00017a

116.Wang, D.; Yang, Y.-L.; Jiang, J.-J.; Shi, M. Org. Biomol. Chem. 2012, 10, 7158-7166. doi:10.1039/c2ob25694k

117.Wei, Y.; Ma, G.-N.; Shi, M. Eur. J. Org. Chem. 2011, 5146-5155. doi:10.1002/ejoc.201100704 
Beilstein J. Org. Chem. 2014, 10, 2089-2121.

\section{License and Terms}

This is an Open Access article under the terms of the Creative Commons Attribution License

(http://creativecommons.org/licenses/by/2.0), which permits unrestricted use, distribution, and reproduction in any medium, provided the original work is properly cited.

The license is subject to the Beilstein Journal of Organic Chemistry terms and conditions:

(http://www.beilstein-journals.org/bjoc)

The definitive version of this article is the electronic one which can be found at:

doi:10.3762/bjoc. 10.218 